\title{
Statistical-Dynamical Seasonal Forecast of Western North Pacific and East Asia Landfalling Tropical Cyclones using the GFDL FLOR Coupled Climate Model $^{\circ}$
}

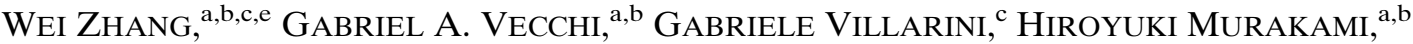 \\ RICHARD GUDGEL, ${ }^{\mathrm{a}}$ AND XIAOSONG YANG $^{\mathrm{a}, \mathrm{d}}$ \\ ${ }^{a}$ National Oceanic and Atmospheric Administration/Geophysical Fluid Dynamics Laboratory, Princeton, New Jersey \\ ${ }^{\mathrm{b}}$ Atmospheric and Oceanic Sciences Program, Princeton University, Princeton, New Jersey \\ ${ }^{\mathrm{c}}$ IIHR-Hydroscience and Engineering, The University of Iowa, Iowa City, Iowa \\ ${ }^{\mathrm{d}}$ University Corporation for Atmospheric Research, Boulder, Colorado

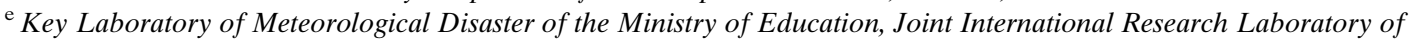 \\ Climate and Environment Change, Collaborative Innovation Center on Forecast and Evaluation of Meteorological \\ Disasters, Nanjing University of Information Science and Technology, Nanjing, China
}

(Manuscript received 2 July 2016, in final form 20 November 2016)

\begin{abstract}
This study attempts to improve the prediction of western North Pacific (WNP) and East Asia (EA) landfalling tropical cyclones (TCs) using modes of large-scale climate variability [e.g., the Pacific meridional mode (PMM), the Atlantic meridional mode (AMM), and North Atlantic sea surface temperature anomalies (NASST)] as predictors in a hybrid statistical-dynamical scheme, based on dynamical model forecasts with the GFDL Forecast-Oriented Low Ocean Resolution version of CM2.5 with flux adjustments (FLOR-FA). Overall, the predictive skill of the hybrid model for the WNP TC frequency increases from lead month 5 (initialized in January) to lead month 0 (initialized in June) in terms of correlation coefficient and root-meansquare error (RMSE). The hybrid model outperforms FLOR-FA in predicting WNP TC frequency for all lead months. The predictive skill of the hybrid model improves as the forecast lead time decreases, with values of the correlation coefficient increasing from 0.56 for forecasts initialized in January to 0.69 in June. The hybrid models for landfalling TCs over the entire East Asian (EEA) coast and its three subregions [i.e., southern EA (SEA), middle EA (MEA), and northern EA (NEA)] dramatically outperform FLOR-FA. The correlation coefficient between predicted and observed TC landfall over SEA increases from 0.52 for forecasts initialized in January to 0.64 in June. The hybrid models substantially reduce the RMSE of landfalling TCs over SEA and EEA compared with FLOR-FA. This study suggests that the PMM and NASST/AMM can be used to improve statistical/hybrid forecast models for the frequencies of WNP or East Asia landfalling TCs.
\end{abstract}

\section{Introduction}

Tropical cyclones (TCs) represent one of the deadliest and costliest natural hazards, responsible for large economic losses and numerous fatalities (e.g., Pielke 1997; Pielke et al. 2008; Zhang et al. 2009), with most of the TCrelated impacts caused by landfalling TCs (e.g., Landsea et al. 1998; Powell and Houston 1998). An accurate and

Supplemental information related to this paper is available at the Journals Online website: http://dx.doi.org/10.1175/ JCLI-D-16-0487.s1.

Corresponding author e-mail: Wei Zhang, wei.zhang@noaa.gov; wei-zhang-3@uiowa.edu timely seasonal prediction of TC frequency and landfall is thus of great significance to the scientific community, governmental administration, and the private sector.

Scientists have attempted to improve the seasonal prediction of TCs through statistical methods, dynamical, and statistical-dynamical models for over three decades (Nicholls 1979; Gray 1984a,b; Gray et al. 1993; Lehmiller et al. 1997; Chan et al. 1998, 2001; Marks and Shay 1998; Elsner and Jagger 2004, 2006; Klotzbach 2007; Fan and Wang 2009; Vecchi et al. 2011, 2013, 2014; Zhao et al. 2010; Villarini and Vecchi 2012, 2013a,b; Villarini et al. 2017; Murakami et al. 2016a,b). As for the western North Pacific (WNP), previous studies built statistical seasonal prediction models for TC frequency (e.g., Chan et al. 1998; Fan 2007, 2010; Fan and Wang 
2009; Lu et al. 2010; Wang et al. 2013; Zhang et al. 2013a, 2016b; Kim et al. 2017) and East Asian landfall (e.g., Liu and Chan 2003; Goh and Chan 2010; Sun and Ahn 2011; Au-Yeung and Chan 2012; Wang et al. 2013; Zhang et al. 2013b, 2016b), achieving encouraging results.

While statistical prediction models have made major progress in producing skillful seasonal predictions, dynamic models including atmospheric general circulation models (AGCMs) and coupled GCMs (CGCMs) have been playing an increasingly important role in the field of TC seasonal prediction (Vitart and Stockdale 2001; Vitart et al. 2003; Vitart 2006; Zhao et al. 2010; Chen and Lin 2011, 2013; Vecchi et al. 2014; Vecchi and Villarini 2014; Camp et al. 2015; Xiang et al. 2015). For the WNP storms, there are numerous studies documenting the results from the use of dynamic models in seasonal predictions of WNP TC frequency (Vitart and Stockdale 2001; Sun and Chen 2011; Au-Yeung and Chan 2012; Chen and Lin 2011, 2013; Vecchi et al. 2014; Camp et al. 2015; Kim et al. 2017; Manganello et al. 2016) and landfall over East Asia (Sun and Ahn 2011; Huang and Chan 2014; Tan et al. 2015).

Over the past several years, there has been a growing interest in the application of statistical-dynamical hybrid models toward predictions of TC activity, with predictions that were quite skillful even for long lead times (e.g., Kim and Webster 2010; Vecchi et al. 2011, 2013, 2014; Villarini and Vecchi 2013a; Li et al. 2013; Kim et al. 2015; Choi et al. 2016a,b; Kim et al. 2017; Villarini et al. 2017; Murakami et al. 2016a; Zhan and Wang 2016; Zhang et al. 2016b). Hybrid models are trained using linear regression or Poisson regression between simulated predictors and observed predictands (e.g., TC frequency or landfall); the trained models are subsequently used to predict the predictands when the dynamical forecasts of the predictors are available (e.g., Vecchi et al. 2011, 2014; Li et al. 2013; Kim et al. 2015; Murakami et al. 2016a; Zhan and Wang 2016; Zhang et al. 2016b). Therefore, hybrid models take advantage both of statistical linkage derived from the observations and dynamic models and of dynamicalmodel-simulated environmental variables relevant to TCs.

The success of the hybrid statistical-dynamical models is built upon the identification of the appropriate predictors representing the genesis, development and tracking of these storms. Over the years, the Pacific meridional mode (PMM; Zhang et al. 2016a), North Atlantic sea surface temperature (SST) anomalies (Huo et al. 2015; Yu et al. 2015; Zhang et al. 2017), and the SST gradient between the southwestern Pacific and the western Pacific warm pool (Zhan et al. 2013) have been found to strongly modulate WNP TC frequency, potentially playing a critical role in the prediction of WNP TC activity. The SST over the Indian Ocean has also been found to influence TC activity in the WNP (Du et al. 2011; Zhan et al. 2011; Tao et al. 2012).
Moreover, recent studies have identified significant links between East Asia landfalling TCs (e.g., over Japan and the Korean Peninsula) and El Niño Modoki/central Pacific El Niño (Zhang et al. 2012), the subtropical high index measured by the 850 -hPa geopotential height $(\mathrm{GPH})$ averaged over the western Pacific (Wang et al. 2013), the Pacific decadal oscillation (PDO) (Chan 2000, 2005; Goh and Chan 2010; Chan et al. 2012), and the Antarctic Oscillation (Wang and Fan 2007). Given the physical connection of these newly identified indices and WNP TC frequency and East Asian TC landfall, we hypothesize that their inclusion in hybrid seasonal prediction schemes will lead to improved skill in predicting these TC quantities.

The predictors for current hybrid models are obtained by averaging the values of variables over selected spatial domains, which are mostly based on correlation analysis between the time series of a predictand (e.g., TC frequency) and simulated large-scale environmental variables (e.g., 500-hPa geopotential height and $850-\mathrm{hPa}$ zonal wind) (e.g., Chan et al. 1998; Li et al. 2013; Choi et al. 2016a,b; Zhan and Wang 2016; Zhang et al. 2016b). Therefore, the spatial domains of a predictor for a dynamic model are difficult to be generalized to other dynamic models (Li et al. 2013; Choi et al. 2016b; Zhan and Wang 2016), significantly limiting the widespread applicability of these hybrid models. Furthermore, most of the current dynamic prediction systems/schemes/ models are generally initialized in all the months (January-June) prior to the period of interest (e.g., JuneNovember for WNP TC activity), providing us with predictions of the covariates for each initialization month. The general strategy is to train the models and verify the forecasts for each initialization month, treating the predictions of the predictors for a given initialization month in isolation from the others. However, by using this approach we are potentially discarding useful information; this is especially true for the shorter lead times, for which more information/dynamical forecasts are available to build hybrid models ("closer gets richer"). Therefore, we hypothesize that the dynamical forecasts prior to a given initialization month (e.g., May) add some value to the system, leading to improved forecasting skill.

In summary, so far hybrid models have been used to make seasonal forecasts for WNP TC frequency and landfall over the East Asian coast. However, the predictors and their spatial domains in a given prediction system are difficult to be generalized, limiting their applicability to other systems. Moreover, the dynamical forecasts obtained prior to an initialized month may be potentially useful but are consistently not taken into consideration to build hybrid models for WNP TC frequency and East Asian landfall. This study attempts to build hybrid seasonal prediction models for basinwide WNP and East Asia 


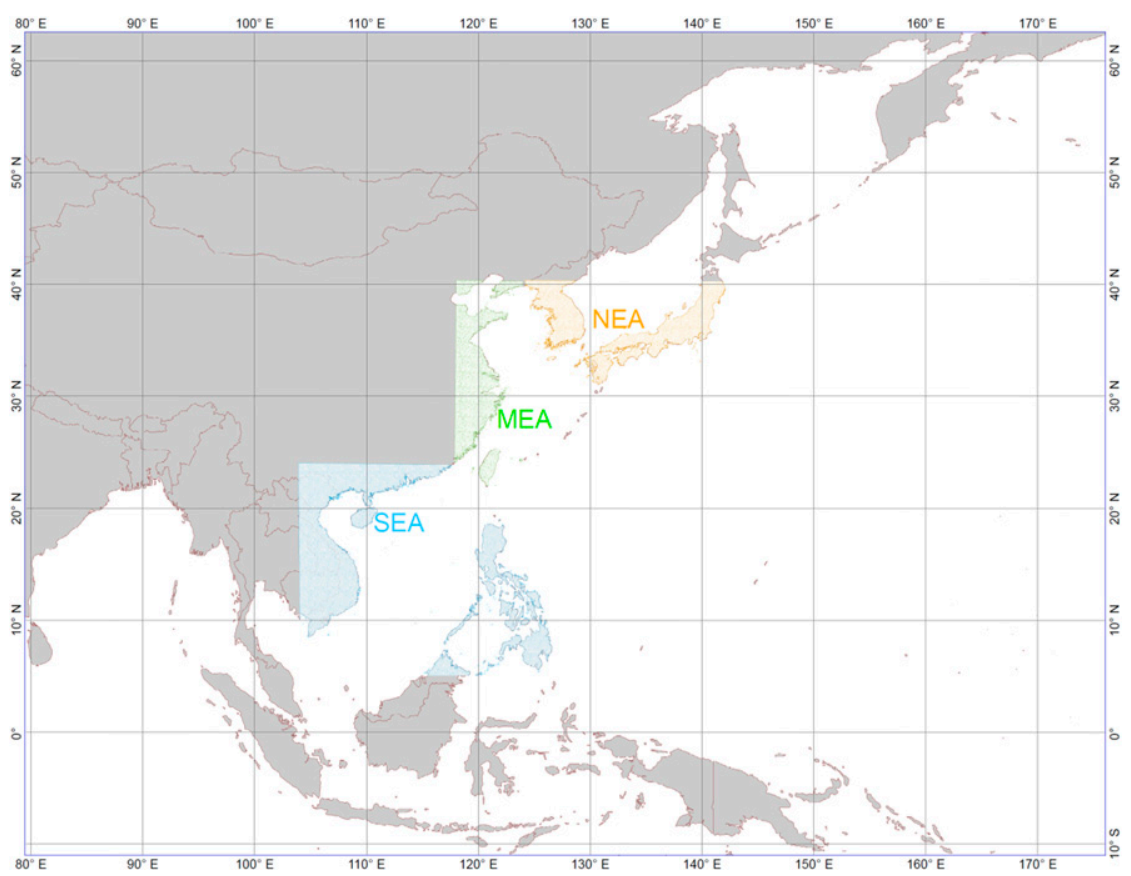

FIG. 1. The southern (blue), middle (green), and northern (orange) part of the East Asian coast used to define TC landfall over East Asia.

landfalling TCs by using well-known and easily processed climate indices (e.g., PMM and Niño-3.4) and developing a new strategy that incorporates the dynamical forecasts prior to the initialization months.

\section{Data and methodology}

\section{a. Data}

TC data are obtained from the International Best Track Archive for Climate Stewardship (IBTrACS; Knapp et al. 2010) for the period of 1980-2014; TC information in 2015 is obtained from the Japanese Meteorology Agency (JMA) best-track data. We use monthly estimates of SST from the Met Office Hadley Centre HadSST3.1.1.0 (Kennedy et al. 2011). The observed large-scale variables are derived from JRA-55 reanalysis data (Kobayashi et al. 2015).

The entire East Asian (EEA) coast is divided into three parts: southern East Asia (SEA), central or middle East Asia (MEA), and northern East Asia (NEA) (Fig. 1), following previous studies (Chan and Xu 2009; Huang and Chan 2014). We build hybrid models for the frequencies of TCs that make landfall over EEA and each subregion (Fig. 1).

\section{b. Climate indices}

Hybrid models are built by training Poisson regression models between predictands (i.e., WNP TC frequency and East Asia landfalling TCs) and predictors. We use predictors that are commonly used and have significant correlation with the frequencies of WNP and East Asian landfalling TCs. Because significant correlation alone cannot justify good performance by the predictors, the predictors should have physical linkage with TC frequency or landfall. Our focus will be on the PMM, the North Atlantic SST Index (NASST), the SST Gradient Index (SSTG), the El Niño index, the Atlantic meridional mode (AMM), the PDO, the Subtropical High Index (STH), and east Indian Ocean SST anomalies (EIO).

PMM is defined as the first maximum covariance analysis (MCA) mode of SST and 10-m wind fields in the eastern Pacific and describes meridional variations in SST, winds, and convection in the tropical Pacific Ocean (Chiang and Vimont 2004). The PMM has robust and significant association with the frequency of WNP TCs in observations and long control experiments (fully coupled free runs) in a high-resolution Geophysical Fluid Dynamics Laboratory (GFDL) coupled climate model (Zhang et al. 2016a).

The North Atlantic SST anomalies are found to strongly modulate WNP TC frequency ( $\mathrm{Li}$ et al. 2013; Huo et al. 2015; Yu et al. 2015; Zhang et al. 2017). This study uses the NASST index defined as the SST anomalies averaged over the region $0^{\circ}-25^{\circ} \mathrm{N}, 90^{\circ} \mathrm{W}-0^{\circ}$, and a base period of 1970-2000. The NASST can mediate vertical wind shear by altering the Walker circulation or the Indian Ocean relaying effect (Yu et al. 2015; Zhang 

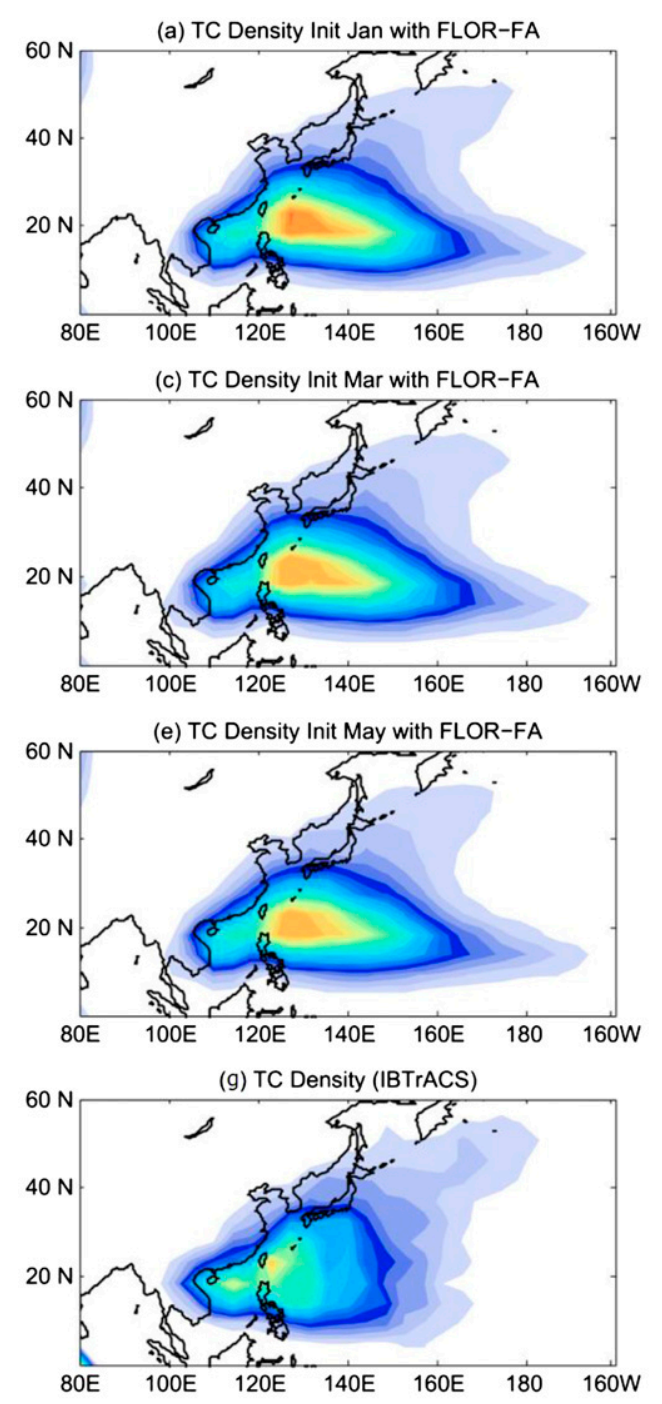

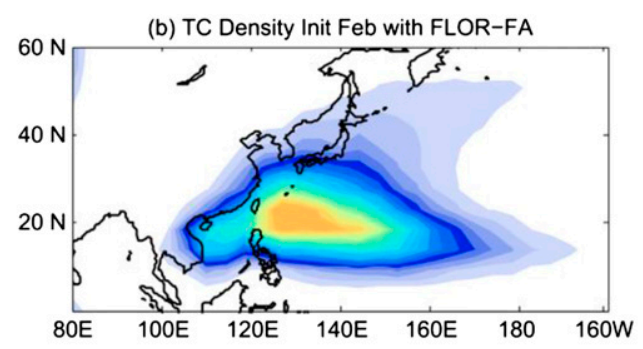

(d) TC Density Init Apr with FLOR-FA
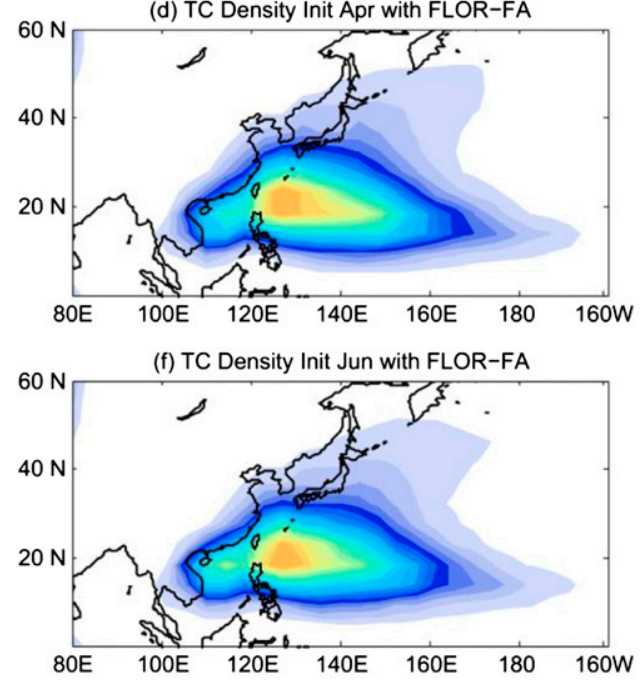

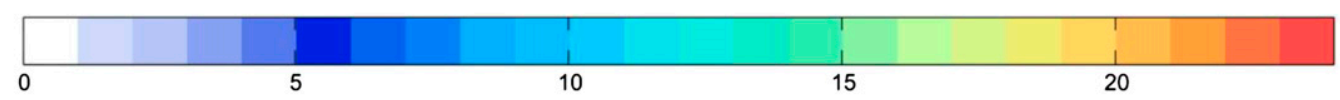

FIG. 2. (a)-(f) Hindcasted TC track density (occurrences) from June to October with FLOR-FA initialized from January to June and (g) observed TC track density in the WNP for the period 1980-2015. The hindcasted TC track density is averaged over 12 members.

et al. 2017). Stronger (weaker) vertical wind shear can strongly suppress (enhance) TC genesis in the WNP (Yu et al. 2015; Zhang et al. 2017).

The SST gradient between the southwestern Pacific and the western Pacific warm pool in spring has strong correlations with WNP TC frequency and has been used in prior studies to build statistical models for the seasonal prediction of WNP TC frequency (Zhan et al. 2013; Zhan and Wang 2016). The SSTG anomaly is responsible for an anomalous cross-equatorial pressure gradient and lowlevel cross-equatorial easterly anomalies over the centralwestern Pacific. The anomalous easterlies enhance local equatorial upwelling and SST cooling in the central $\mathrm{Pa}$ cific, which suppress WNP TC genesis (Zhan et al. 2013; Zhan and Wang 2016). The SSTG index is defined as the SST differences averaged over $0^{\circ}-16^{\circ} \mathrm{N}, 125^{\circ}-165^{\circ} \mathrm{E}$ minus those over $40^{\circ}-20^{\circ} \mathrm{S}, 160^{\circ} \mathrm{E}-170^{\circ} \mathrm{W}$.

The Niño- 3 region is bounded by $5^{\circ} \mathrm{S}-5^{\circ} \mathrm{N}$ and $150^{\circ}-$ $90^{\circ} \mathrm{W}$. The Niño-3.4 region is bounded by $5^{\circ} \mathrm{N}-5^{\circ} \mathrm{S}$ and $170^{\circ}-120^{\circ} \mathrm{W}$. The El Niño Modoki Index (EMI) is used to measure the SST anomaly in the central Pacific. ENSO indices during the early season have been used to predict WNP TC frequency and landfalling TCs over East Asia (Chan et al. 1998; 2001). The EMI is closely 

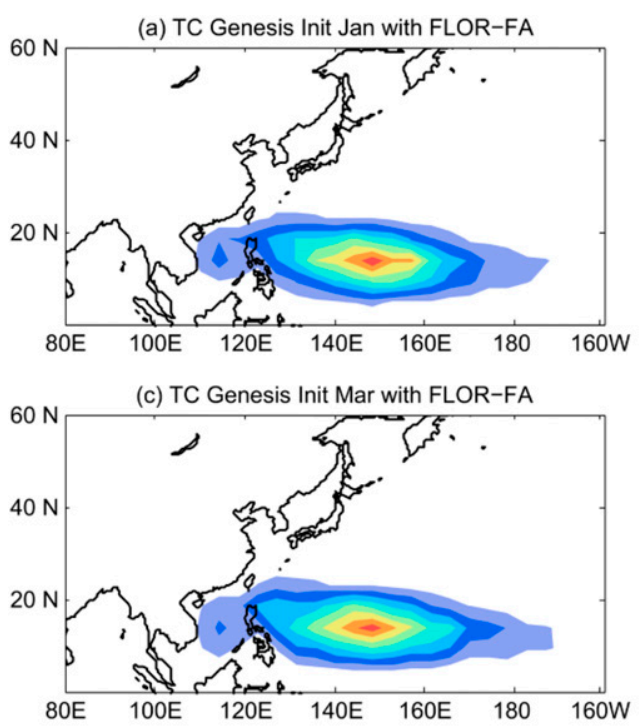

(e) TC Genesis Init May with FLOR-FA

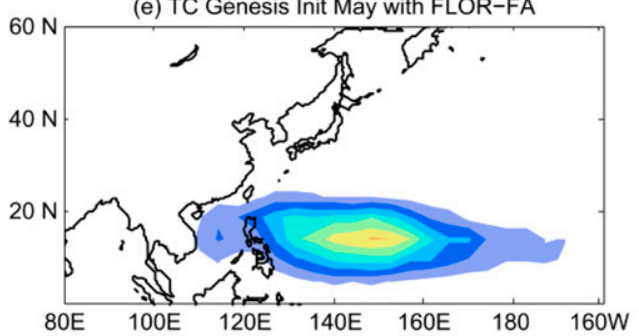

(g) TC Genesis IBTrACS

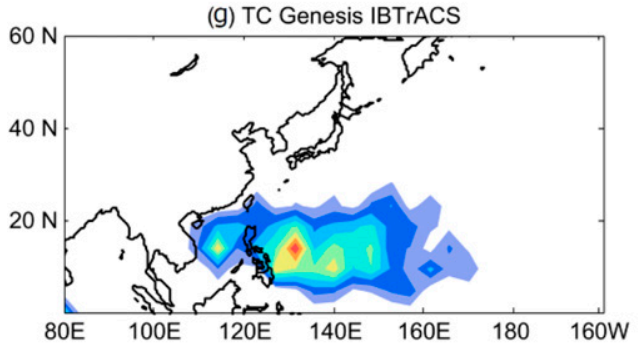

(b) TC Genesis Init Feb with FLOR-FA

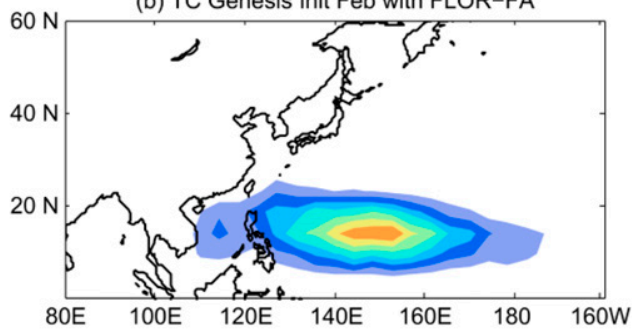

(d) TC Genesis Init Apr with FLOR-FA

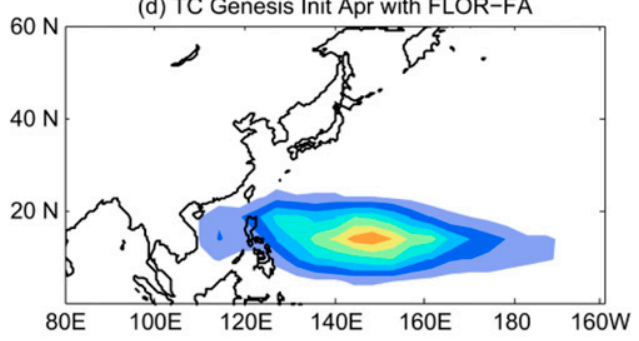

(f) TC Genesis Init Jun with FLOR-FA

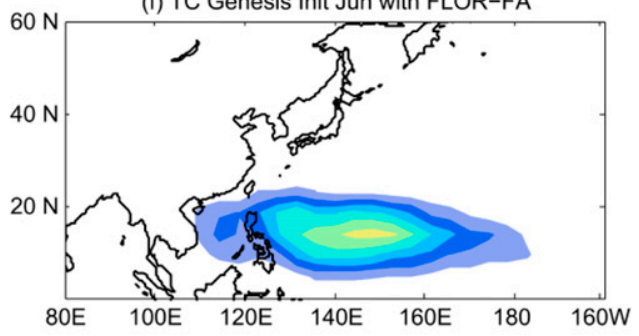

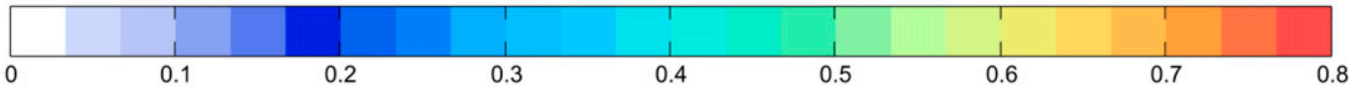

FIG. 3. As in Fig. 2, but for the hindcasted TC genesis density.

associated with TC landfall over Japan and the Korean Peninsula (NEA) (Zhang et al. 2012). The EMI is defined as EMI $=[\mathrm{SSTA}]_{\mathrm{A}}-0.5[\mathrm{SSTA}]_{\mathrm{B}}-0.5[\mathrm{SSTA}]_{\mathrm{C}}$, where $[\mathrm{SSTA}]_{\mathrm{A}},[\mathrm{SSTA}]_{\mathrm{B}}$, and $[\mathrm{SSTA}]_{\mathrm{C}}$ indicate the SST anomalies averaged over the regions $\left(10^{\circ} \mathrm{S}-10^{\circ} \mathrm{N}\right.$, $\left.165^{\circ} \mathrm{E}-140^{\circ} \mathrm{W}\right),\left(15^{\circ} \mathrm{S}-5^{\circ} \mathrm{N}, 110^{\circ}-70^{\circ} \mathrm{W}\right)$, and $\left(10^{\circ} \mathrm{S}-20^{\circ} \mathrm{N}\right.$, $125^{\circ}-145^{\circ} \mathrm{E}$ ), respectively (Ashok et al. 2007). The EMI will be used as a predictor for TC landfall over NEA.

The Atlantic meridional mode is known historically as the Atlantic dipole or interhemispheric mode (Servain 1991; Xie and Philander 1994; Carton et al. 1996) or the tropical Atlantic gradient mode (Chiang et al. 2002).
The AMM is closely linked to the Atlantic multidecadal oscillation (AMO) (Kossin and Vimont 2007; Vimont and Kossin 2007; Grossmann and Klotzbach 2009). Recently, the AMM has been linked to WNP TC activity by mediating the Walker circulation (Zhang et al. 2017).

The PDO is a strong atmosphere-ocean oscillation in the North Pacific (Mantua et al. 1997; Newman et al. 2016). Different physical processes including highfrequency atmospheric forcing, teleconnections from the tropical Pacific, and ocean Rossby waves lead to the variability of the PDO on a variety of time scales (e.g., seasonal, interannual, and decadal) (Newman et al. 

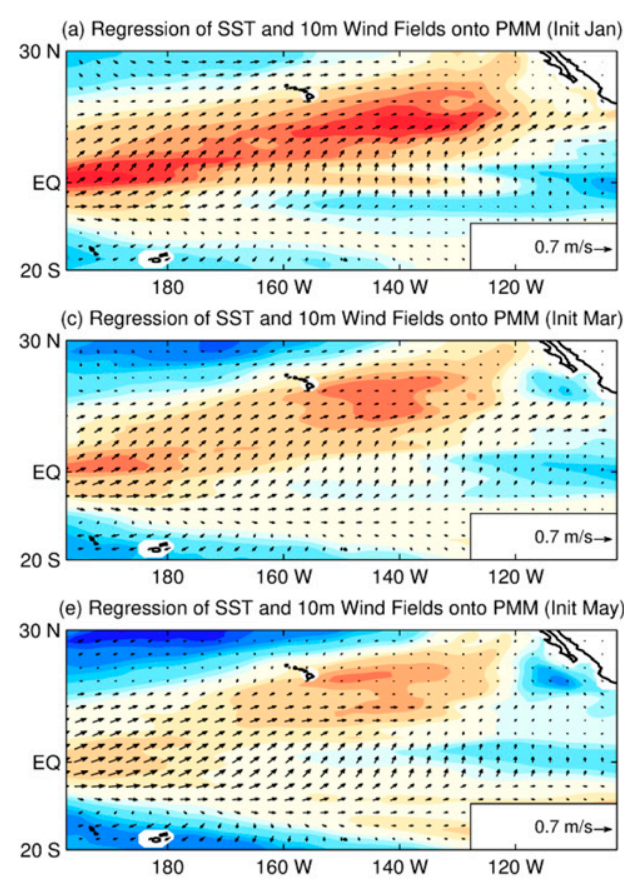

(g) Regression of SST and $10 \mathrm{~m}$ Wind Fields onto PMM (Obs)
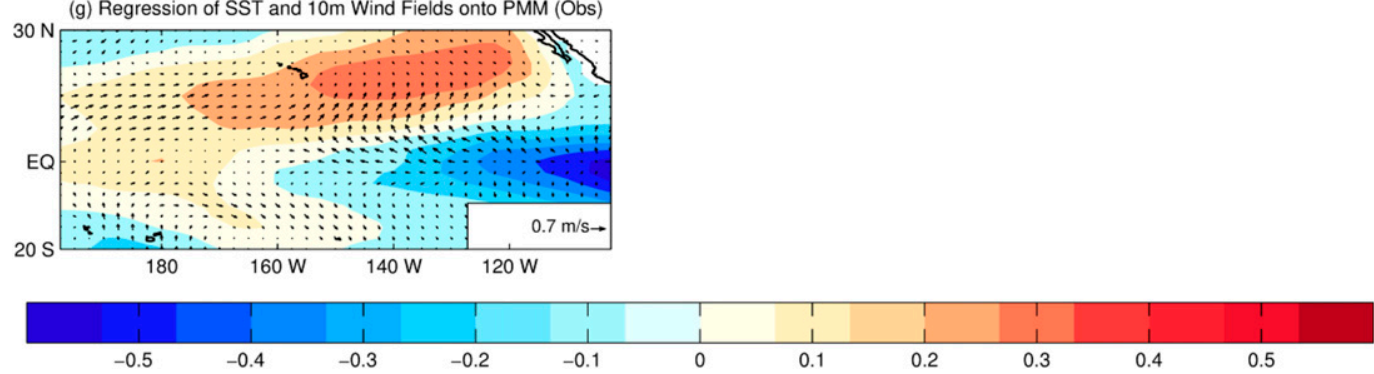

FIG. 4. Predicted PMM with FLOR-FA in initialization months January-June and observed PMM represented by SST anomalies (shading; ${ }^{\circ} \mathrm{C}$ ) and $10-\mathrm{m}$ surface wind fields (vector; $\mathrm{m} \mathrm{s}^{-1}$ ).
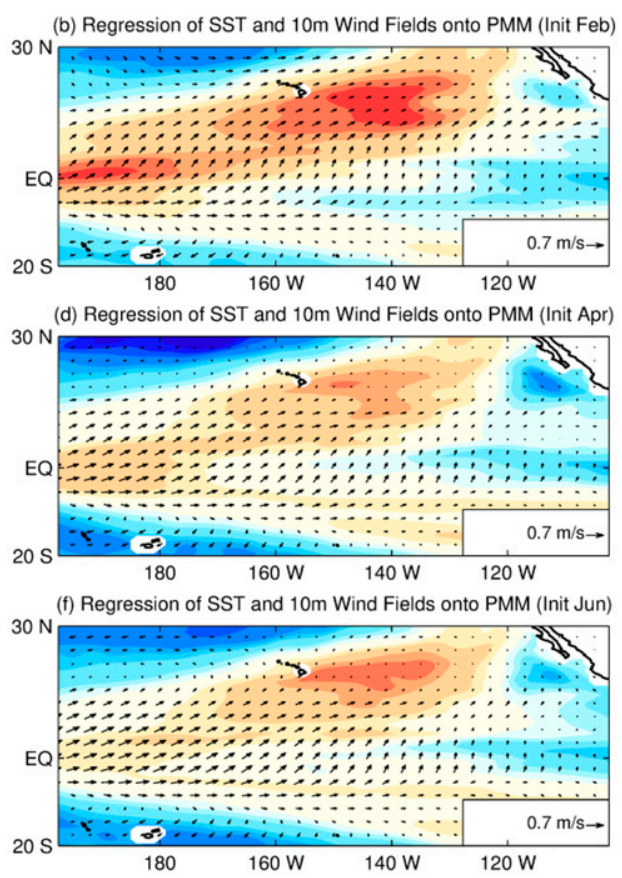
(a) Correlation between Obs and Sim SST (JJASO) Init Jan FLOR-FA

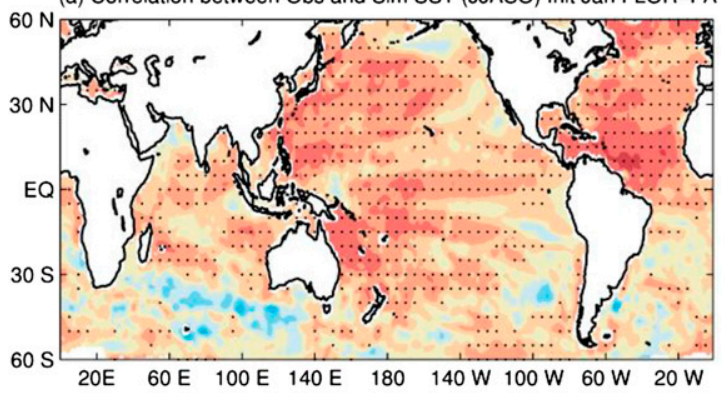

(c) Correlation between Obs and Sim SST (JJASO) Init Mar FLOR-FA

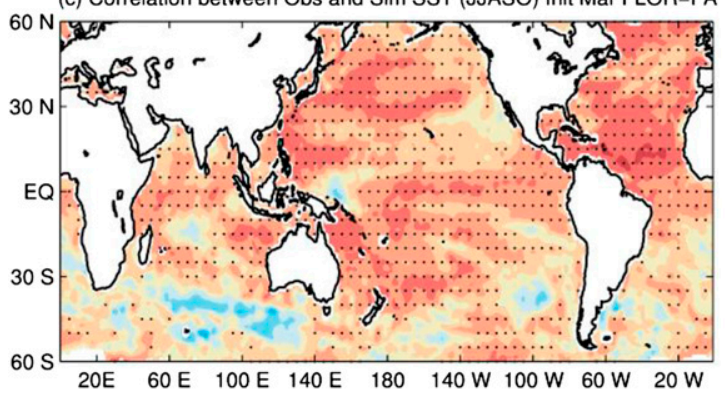

(e) Correlation between Obs and Sim SST (JJASO) Init May FLOR-FA

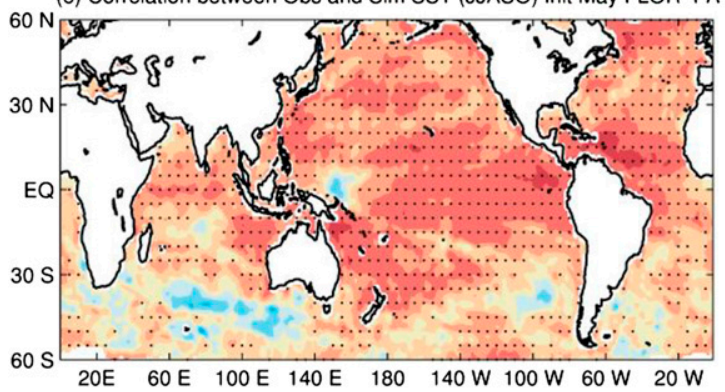

(b) Correlation between Obs and Sim SST (JJASO) Init Feb FLOR-FA

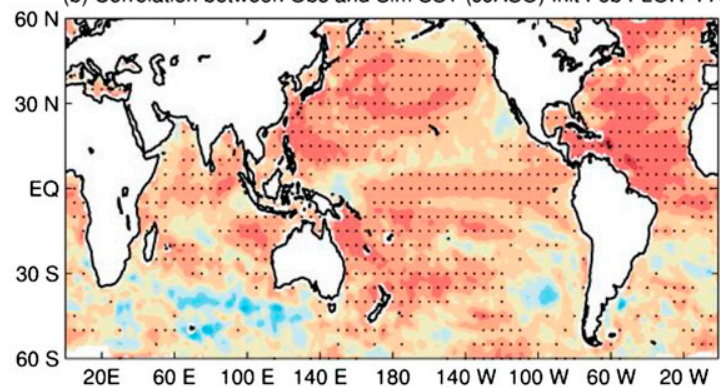

(d) Correlation between Obs and Sim SST (JJASO) Init Apr FLOR-FA

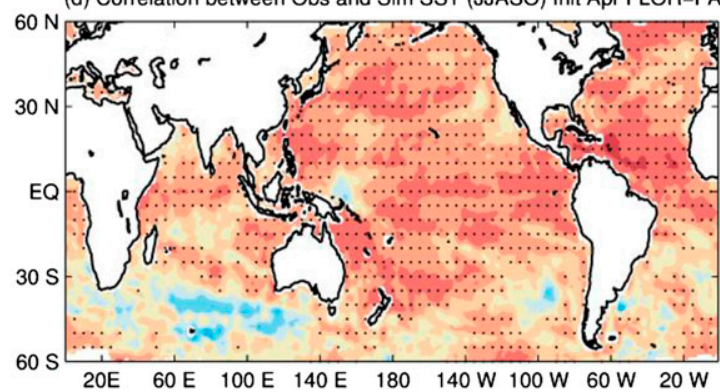

(f) Correlation between Obs and Sim SST (JJASO) Init Jun FLOR-FA

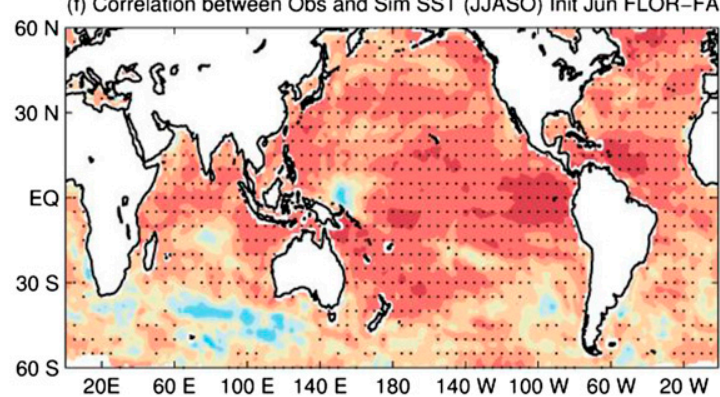

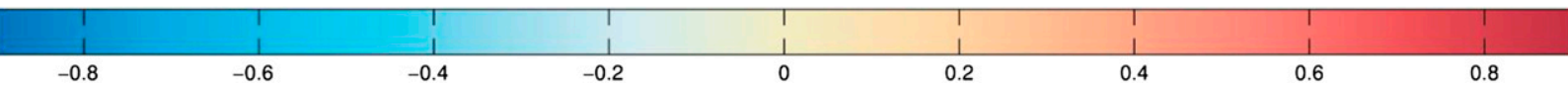

FIG. 5. Pointwise correlation coefficient between predicted (FLOR-FA) and observed SST anomalies averaged over the June-October months for different initialized months (from January to June). Stippled regions are those for which the correlation coefficients are statistically different from zero at the 0.05 significance level.

climatology (FLOR-FA; Vecchi et al. 2014; Delworth et al. 2015). The detailed description of FLOR is provided in Vecchi et al. (2014).

We used 12-member ensemble retrospective seasonal forecasts initialized on the first day of every month from 1980 to the present (Vecchi et al. 2014). The GFDL's ensemble coupled data assimilation (ECDA) system is used to initialize FLOR (Zhang et al. 2007; Zhang and Rosati 2010; Yang et al. 2013, 2015; Vecchi et al. 2011, 2013, 2014; Jia et al. 2015; Msadek et al. 2014a,b; Krishnamurthy et al. 2016). Chang et al. (2013) comprehensively assessed the 1960-2010 oceanic variability in the newest version of the ECDA. The ECDA system provides initial conditions for the ocean and ice components of the FLOR while the initial conditions for the atmosphere and land components of FLOR are obtained from FLOR's simulations forced with the observed estimates of SSTs (Vecchi et al. 2014).

\section{d. Closer-gets-richer strategy}

To make the best use of the dynamic forecasts produced by FLOR-FA, we use the "closer-gets-richer" strategy to build hybrid prediction models. In forecasts produced by dynamic models, zero-lead-month predictions (i.e., initialized in June for WNP TC activity) are not necessarily better than those obtained for longer lead times (e.g., initialized in January or February), partly due to initial shock (e.g., Schneider et al. 1999; 


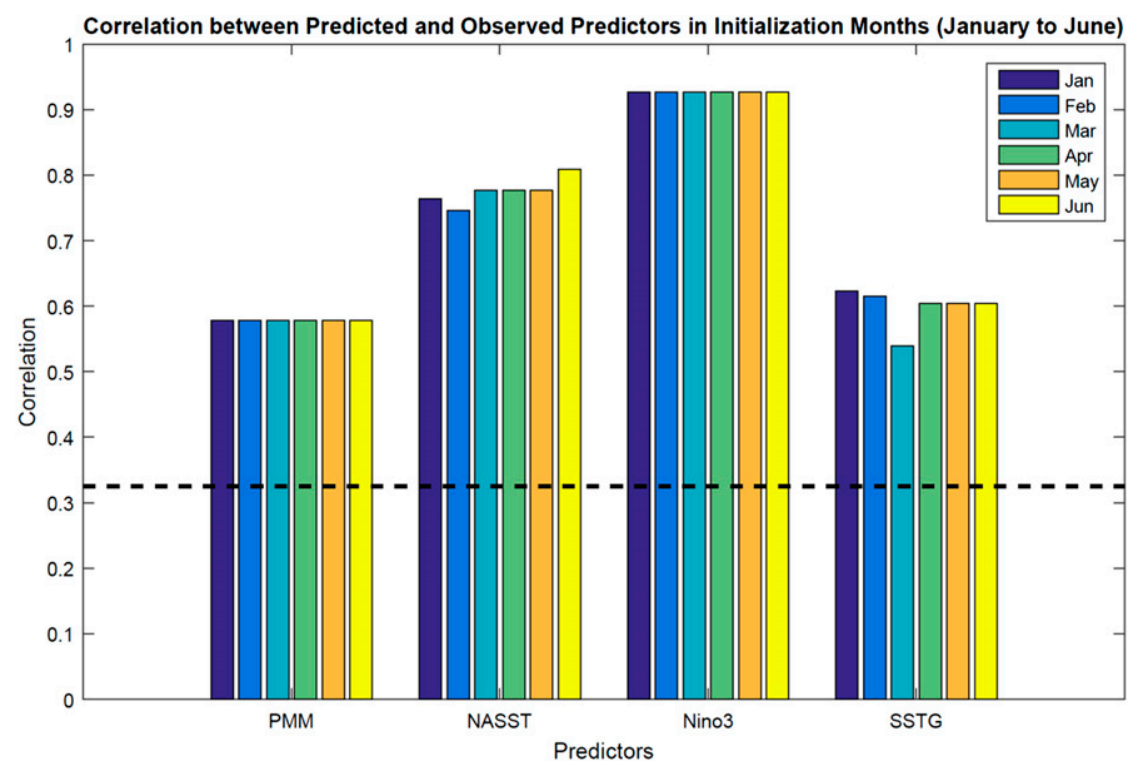

FIG. 6. Values of the correlation coefficient between observed and FLOR-FA predicted PMM, NASST index, Niño-3, and SSTG. The black dashed line represents the value for which the correlation coefficients are significantly different from zero at the 0.05 significance level.

Luo et al. 2005; Zhang 2011). FLOR-FA produces better predictions for WNP TC frequency when initialized in January rather than in July (Zhang et al. 2016b). Here we develop a new strategy that we refer to as closer-getsricher to overcome this limitation in dynamical seasonal forecasting when building hybrid models. The closergets-richer strategy is defined as follows. Conventionally, we only use dynamical forecasts for one initialization month to build the hybrid model for that specific initialization month. In the closer-gets-richer strategy, however, we use all the dynamical forecasts available for and prior to the initialization month to build hybrid models: we include the predictors from the dynamical forecasts prior to the initialization month of interest if they can improve the hybrid model compared to the results we would obtain using only the predictions for the initialization month of interest. Under this strategy, if the prediction using dynamic forecasts initialized in and before June cannot outperform that using the prediction initialized in or before May, we select the prediction by using dynamic forecasts initialized in May as that for June. By doing this, the hybrid model cannot provide a worse performance as the lead time decreases, alleviating some of the issues associated with the forecasting of WNP TC activity based on FLORFA (Zhang et al. 2016b).

\section{e. Poisson regression}

We use Poisson regression to model the occurrence probability of TCs in the forecast experiments with

TABLE 1. The predictors from the dynamic forecasts of FLOR-FA used to build the hybrid model for WNP TC frequency. "PMM (FebJun; initial Jan)" represents the predicted PMM index averaged from February to June and initialized in January. The others are defined likewise.

\begin{tabular}{cc}
\hline \hline Initial month & Predictors \\
\hline Jan & PMM (Feb-Jun; initial Jan), NASST (Jun-Oct; initial Jan), SSTG (Jun-Oct; initial Jan), and Niño-3 \\
& (Mar-May; initial Jan) \\
Feb & PMM (Feb-Jun; initial Jan), NASST (Jun-Oct; initial Feb), SSTG (Jun-Oct; initial Feb), and Niño-3 \\
& (Mar-May; initial Jan) \\
Mar & PMM (Feb-Jun; initial Jan), NASST (Jun-Oct; initial Mar), SSTG (Jun-Oct; initial Mar), and Niño-3 \\
& (Mar-May; initial Jan) \\
Apr & PMM (Feb-Jun; initial Jan), NASST (Jun-Oct; initial Mar), SSTG (Jun-Oct; initial Apr), and Niño-3 \\
May & (Mar-May; initial Jan) \\
& PMM (Feb-Jun; initial Jan), NASST (Jun-Oct; initial Mar), SSTG (Jun-Oct; initial Apr), and Niño-3 \\
June & (Mar-May; initial Jan) \\
& PMM (Feb-Jun; initial Jan), NASST (Jun-Oct; initial Mar), SSTG (Jun-Oct; initial Apr), and Niño-3 \\
\hline
\end{tabular}



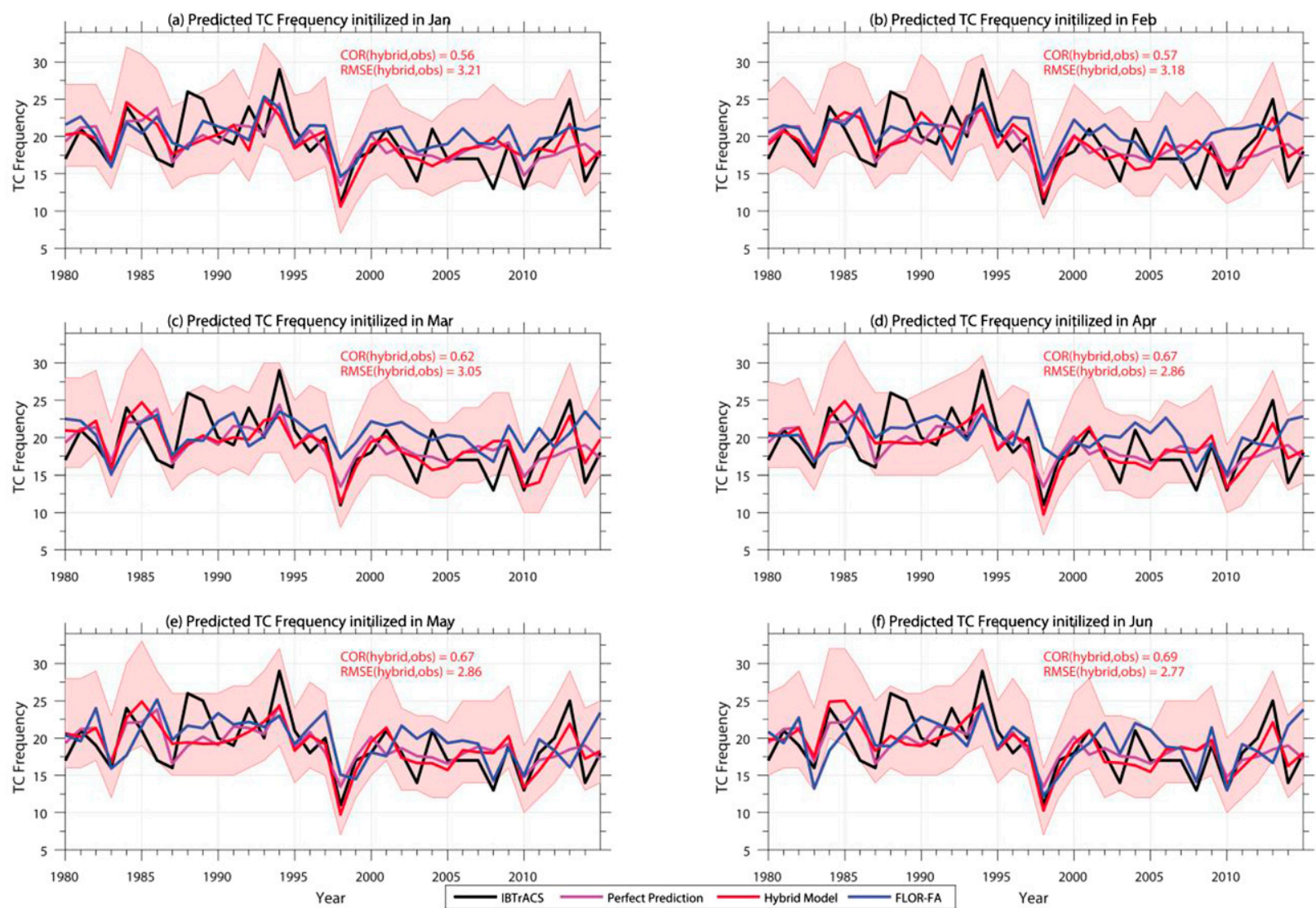

FIG. 7. Correlation and RMSE of observed and predicted WNP TC frequency produced by the hybrid model after LOOCV for 1980 2015. The red and purple curves denote the predictions of WNP TC frequency in each year using the hybrid model and "perfect prediction" using observed predictors, while the black solid lines represent the observations. The blue curves represent predicted TC frequency with FLOR-FA. The pink areas represent the $10 \%$ and $90 \%$ percentiles of 1000 random samples of TC frequency given $\mu$ (the predicted mean TC frequency with the hybrid model) under the Poisson distribution.

FLOR. Many studies have used Poisson regression to examine the occurrence probability of rare events (e.g., Elsner and Schmertmann 1993; Elsner and Jagger 2006; Villarini et al. 2010; Wilks 2011). Poisson regression is described as

$$
P\left(Y_{i}=y\right)=\frac{\mu_{i}^{y} e^{-\mu_{i}}}{y !}, \quad y=0,1,2, \ldots, \infty,
$$

where $\log \left(\mu_{i}\right)=\beta_{0}+\sum \beta_{j} x_{i j}$.

The term $Y_{i}$ represents the true number of TC frequency in the $i$ th year, while $\mu_{i}$ denotes the logarithm of the average landfalling/WNP TC frequency and $y$ denotes the observed landfalling/WNP TC frequency; $\mu_{i}$ can be represented as a linear combination of the predictors $x_{i j}$, with $j$ being the specified predictor during the year $i ; \beta_{j}$ and $\beta_{0}$ represent the corresponding Poisson regression coefficient and the intercept, respectively. A similar description can be found in Zhang et al. (2016b).

\section{Results}

Figure 2 illustrates predicted and observed TC track densities during the peak TC season [June-October (JJASO)]. TCs in FLOR-FA are tracked from the 6-hourly model output by using the tracker developed at GFDL as implemented in previous studies (e.g., Murakami et al. 2016a; Zhang et al. 2016a,b,c, 2017; see the appendix for details). The basic structures of the observed TC track density are well simulated by FLORFA. However, there are positive biases in TC density in the region $120^{\circ}-140^{\circ} \mathrm{E}$ with FLOR-FA compared with

TABLE 2. The predictive skill of the "perfect prediction" that uses observed predictors for WNP TCF and landfall over SEA, MEA, NEA, and EEA.

\begin{tabular}{lccccc}
\hline \hline Perfect prediction & WNP TCF & SEA & MEA & NEA & EEA \\
\hline Correlation & 0.59 & 0.57 & 0.53 & 0.45 & 0.69 \\
RMSE & 3.06 & 1.74 & 1.32 & 1.92 & 2.12 \\
\hline
\end{tabular}



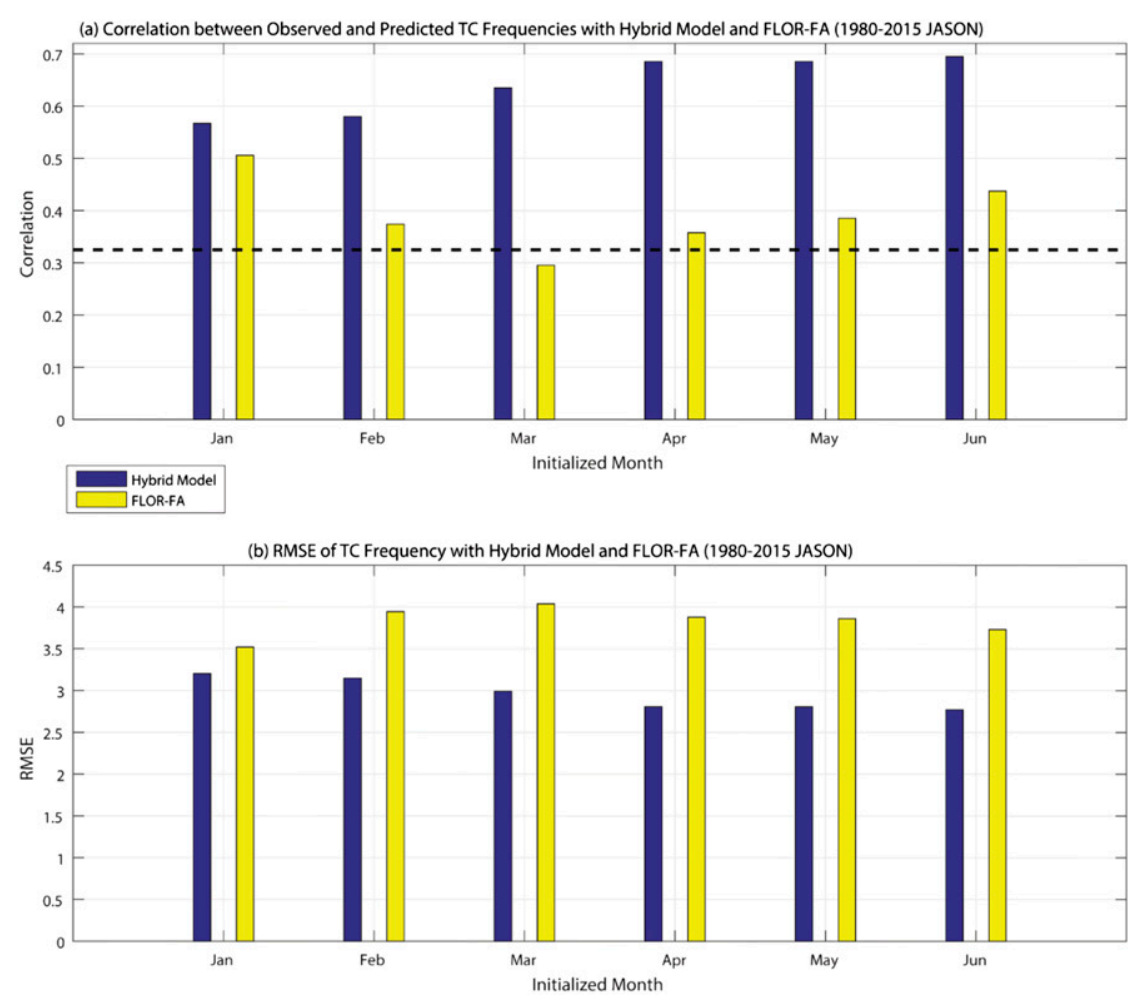

FIG. 8. (a) Correlation and (b) RMSE of predicted and observed WNP TC frequencies using the hybrid model (blue) and FLOR-FA (yellow) for initialization months from January to June after LOOCV. The black dashed line in the top panel represents the value for which the correlation coefficients are significantly different from zero at the 0.05 significance level.

the observations (Fig. 2). The predicted TC density climatology with FLOR-FA is similar to one another (Fig. 2a-f). The climatology of TC density in the South China Sea is realistically simulated in FLOR-FA; this is particularly true when initialized in June. The predicted climatology of TC density in the WNP has biases along the East Asian coast partly due to the eastward shift in TC genesis and density, limiting the capability of FLORFA in successfully forecasting TC landfalls over East Asia. A detailed discussion of TC landfall is provided in section $3 b$.

The forecasted WNP TC genesis density has a magnitude close to observations while the spatial patterns are different (Fig. 3). Similar to the simulated WNP TCs in control experiments with FLOR-FA (e.g., Vecchi et al. 2014; Zhang et al. 2016a,b), the high center of TC genesis density in seasonal-forecast experiments has an eastward shift compared with observations (Fig. 3). Specifically, there is a high center of TC genesis around $135^{\circ} \mathrm{E}$ in the observations whereas it is shifted to around $145^{\circ} \mathrm{E}$ in the FLOR-FA forecasts (Fig. 3). In addition, the climatology of TC genesis density in the South China Sea is much lower than that in observations. Similar to the forecasts of the TC track density, the forecasts initialized in June outperform those in the other initialization months.

\section{a. Hybrid model for WNP TC frequency}

Here we use the predictors introduced in section $2 \mathrm{~b}$ to build the hybrid prediction model for WNP TC frequency. To further justify their use, we provide the predictive skill of FLOR-FA for these predictors. Figure 4 shows the predicted PMM with FLOR-FA initialized from January to June. The predicted PMM successfully captures fundamental structures of the observed PMM characterized by warm SST anomalies located from the central Pacific to the subtropical eastern Pacific, and by negative SST anomalies in the tropical

TABLE 3. List of predictors in dynamic forecasts of FLOR-FA used to build the hybrid model for TC landfall over SEA, MEA, NEA, and EEA.

\begin{tabular}{cl}
\hline \hline Landfall regions & \multicolumn{1}{c}{ Predictors } \\
\hline SEA & PDO, NASST, AMM, PMM, Niño-3 \\
MEA & PDO, NASST, AMM, Niño-3, EIO \\
NEA & PDO, EMI, STH, Niño-3 \\
EEA & PDO, NASST, PMM, EIO \\
\hline
\end{tabular}




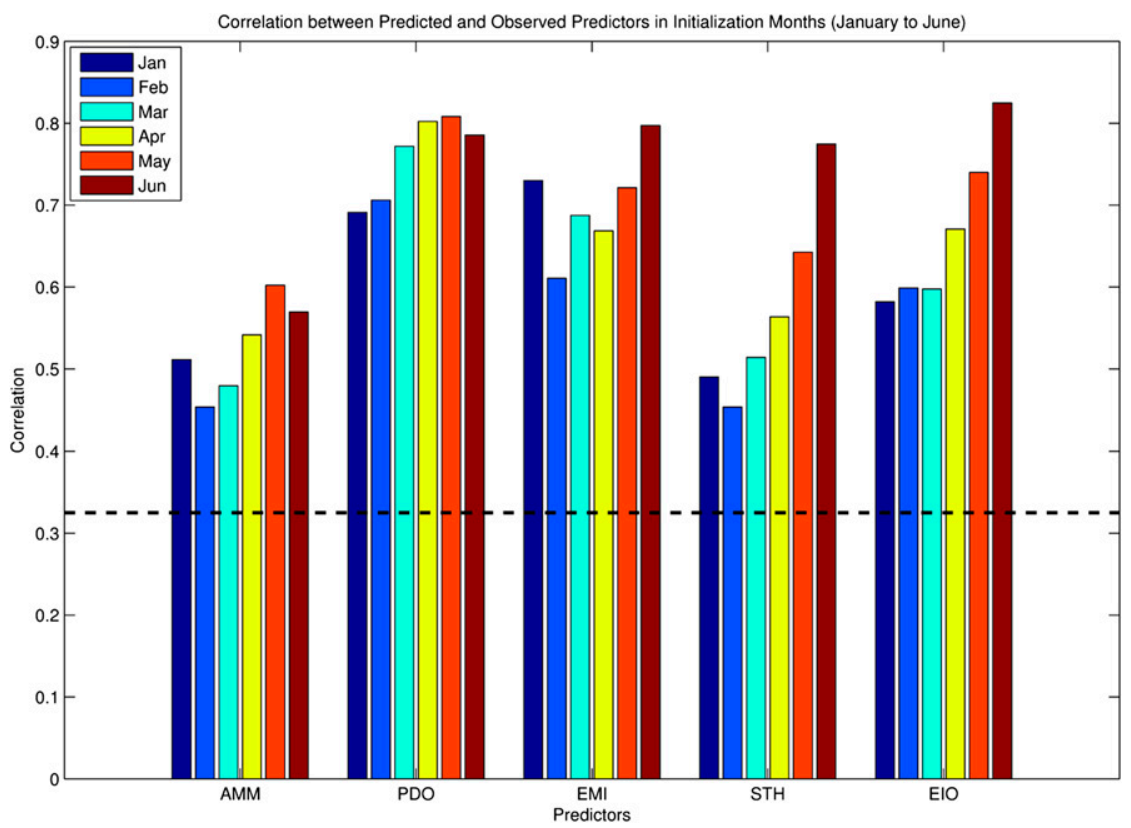

FIG. 9. Values of the correlation coefficient between observed and predicted (FLOR-FA) AMM, PDO, EMI, STH, and EIO. The black dashed line represents the value for which the correlation coefficients are significantly different from zero at the 0.05 significance level.

eastern Pacific (Fig. 4). Note that the surface wind anomalies of the predicted PMM in the subtropical eastern Pacific are quite weak, especially initialized after February (Fig. 4).

The predictors Niño-3, SSTG, and NASST are calculated from predicted SST anomalies with FLOR-FA. It is therefore useful to assess the skill of FLOR-FA in predicting SST. The predictive skill of FLOR-FA for SST is generally high for all initialization months, and it is higher when the dynamic model is initialized closer to the target months (Fig. 5). The high predictive skill of FLOR-FA for SST strongly supports the use of Niño-3, SSTG, and NASST for the hybrid prediction model. Figure 6 illustrates the correlation between predicted and observed predictors which are used to build the hybrid model. All correlation coefficients between predicted and observed predictors are significant (Fig. 6). The predictive skill for PMM is slightly lower than that for Niño-3, NASST, and SSTG (Fig. 6). It is noted that the PMM and Niño-3 indices in the hybrid model are taken from the forecasts initialized in January for February-June and those for March-May, respectively. Therefore, the correlation coefficients between observed and predicted PMM in February-June Niño-3 in March-May are the same for different initialization months (Fig. 6).

Using the "closer-gets-richer" strategy in which the predictors in or before an initialization month are

TABLE 4. List of predictors for TC landfall over SEA for different initialization months. "PMM (Feb-Jun; initial Jan)" represents the predicted PMM index averaged from February to June and initialized in January. The others are defined likewise.

\begin{tabular}{cc}
\hline \hline Initial month & Predictors \\
\hline Jan & PMM (Feb-Jun; initial Jan), NASST (Jun-Oct; initial Jan), Niño-3 (Jun-Oct; initial Jan), AMM (Jun-Oct; \\
& initial Jan), and PDO (Jun-Oct; initial Jan) \\
Feb & PMM (Feb-Jun; initial Jan), NASST (Jun-Oct; initial Feb), Niño-3 (Jun-Oct; initial Jan), AMM (Jun-Oct; \\
& initial Feb), and PDO (Jun-Oct; initial Feb) \\
Mar & PMM (Feb-Jun; initial Jan), NASST (Jun-Oct; initial Feb), Niño-3 (Jun-Oct; initial Jan), AMM (Jun-Oct; \\
& initial Feb), and PDO (Jun-Oct; initial March) \\
Apr & PMM (Feb-Jun; initial Jan), NASST (Jun-Oct; initial Apr), Niño-3 (Jun-Oct; initial Jan), AMM (Jun-Oct; \\
initial Feb), PDO, and (Jun-Oct; initial Apr) & \\
May & PMM (Feb-Jun; initial Jan), NASST (Jun-Oct; initial Apr), Niño-3 (Jun-Oct; initial Jan), AMM (Jun-Oct; \\
Initial May), and PDO (Jun-Oct; initial Apr) & \\
Jun & PMM (Feb-Jun; initial Jan), NASST (Jun-Oct; initial Apr), Niño-3 (Jun-Oct; initial Jan), AMM (Jun-Oct; \\
& initial Jun), and PDO (Jun-Oct; initial Apr)
\end{tabular}



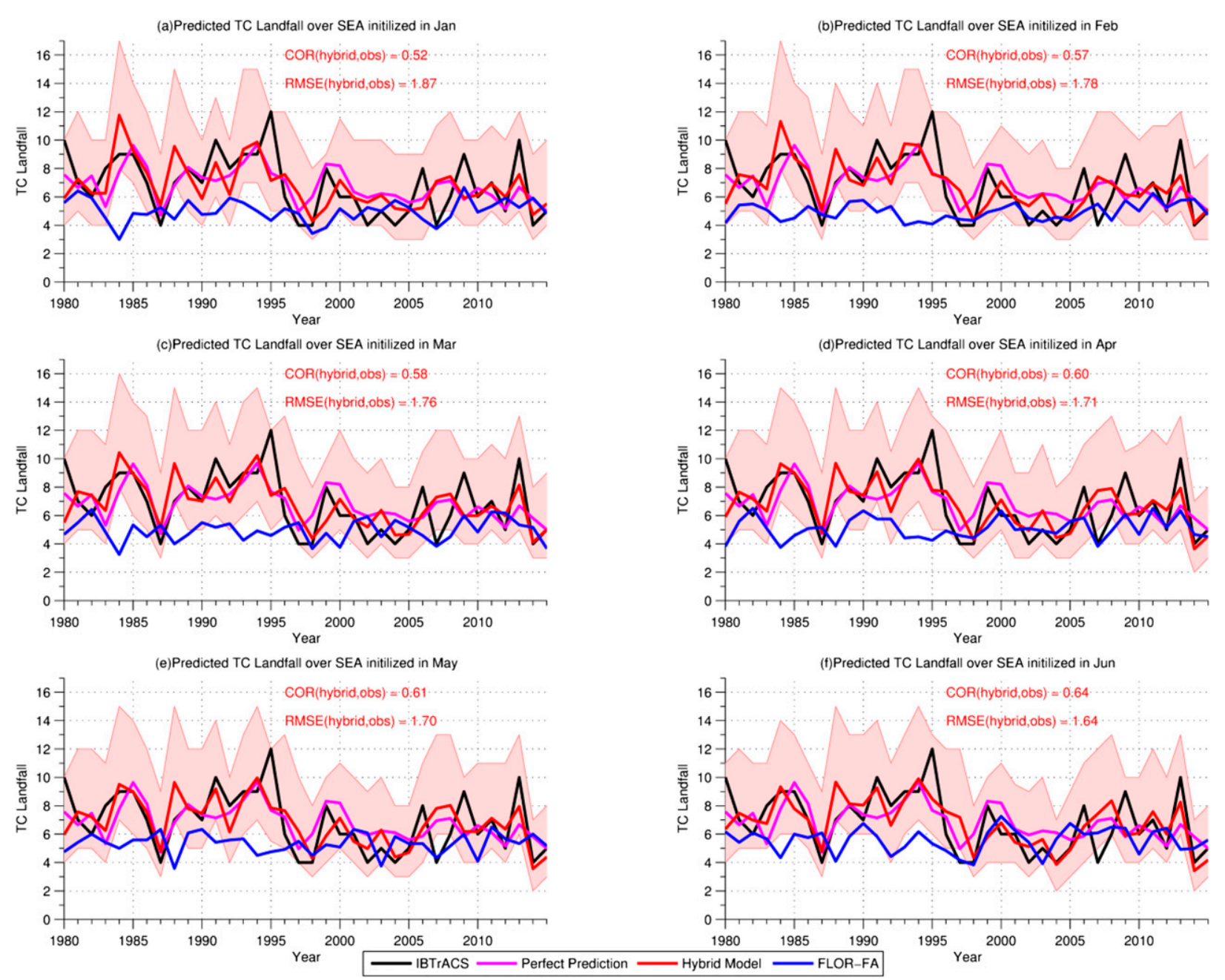

FIG. 10. As in Fig. 7, but for TC landfall over SEA.

allowed to be used for the hybrid model, the predictors in different initialization months are listed in Table 1. The predictors are selected as follows. First, the predictors should be closely associated with WNP TC frequency in the observations and in FLOR-FA. Second, a predictor is used when it produces significant correlation with the observations after leave-one-out crossvalidation (LOOCV) with the hybrid model. Third, the predictors should be commonly used and easily processed to make these results directly applicable in other studies. When the forecasts are initialized closer to the target months (e.g., JJASO), more information is available to build the hybrid model.

The hybrid model initialized in January produces predictions with a correlation of 0.56 between predicted and observed WNP TC frequency and a RMSE of 3.21 after LOOCV (Fig. 7a). The hybrid model initialized in January predicts WNP TC frequency in 2015 close to the observations, while FLOR-FA substantially overestimates the WNP TC frequency for forecasts initialized in January (Fig. 7a). The predictive skill of the hybrid model becomes better when we get closer to the target TC season, with the values of the correlation coefficient increasing from 0.56 to 0.71 as the initialization month decreases from January to June (Fig. 7). At the shortest lead time (June initialized), the correlation between the WNP TC frequencies in observations and the hybrid model reaches 0.69 and an RMSE of 2.77, which is quite promising compared with the predictive skill of current prediction models (Huang and Chan 2014; Li et al. 2013; Kim et al. 2017). The "perfect prediction" using observed predictors produces a correlation coefficient of 0.59 and an RMSE of 3.06, which is slightly lower than the skill achieved from the hybrid model initialized in April to June (Table 2). This supports the importance of the predictors in predicting WNP TC frequency. 
(a) Correlation Pre and Obs Landfall SEA with Hybrid Model and FLOR-FA

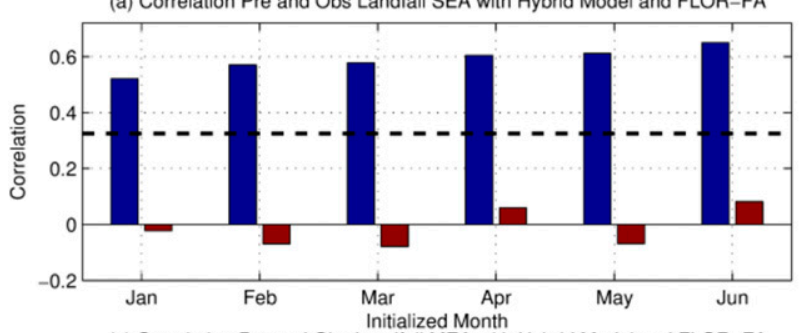

(c) Correlation Pre and Obs Landfall MEA with Hybrid Model and FLOR-FA

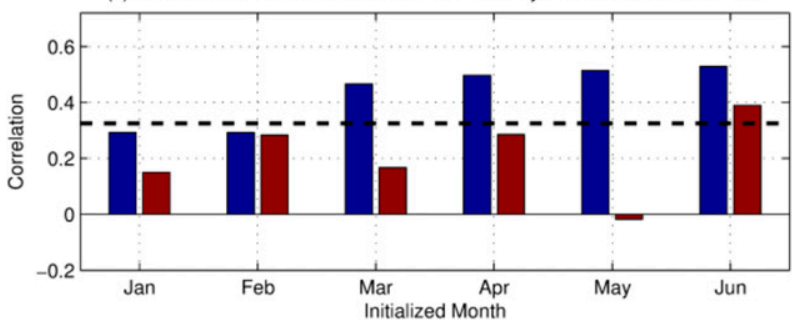

(e) Correlation Pre and Obs Landfall NEA with Hybrid Model and FLOR-FA

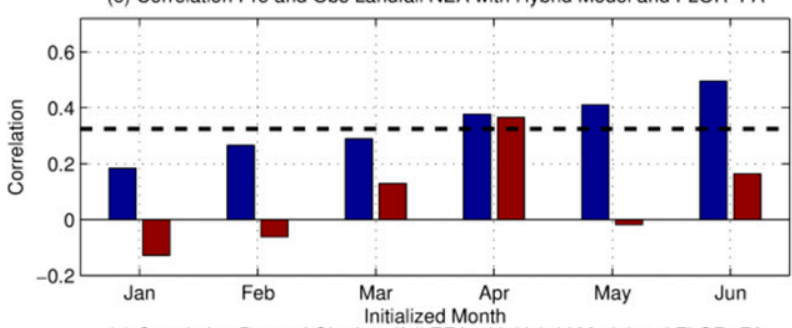

(g) Correlation Pre and Obs Landfall EEA with Hybrid Model and FLOR-FA

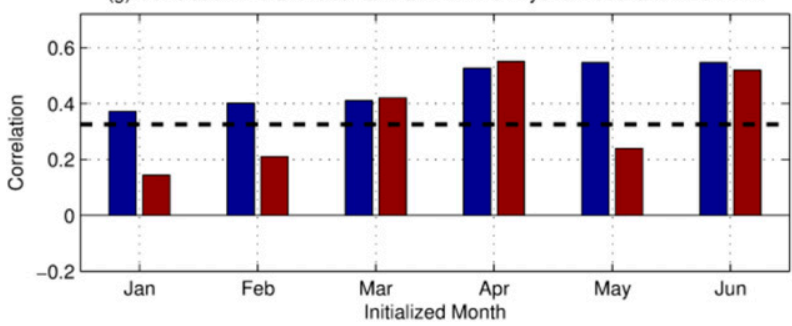

(b) RMSE of Landfall SEA with Hybrid Model and FLOR-FA

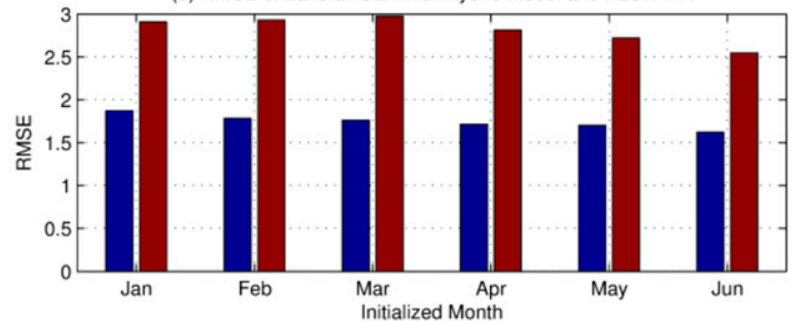

(d) RMSE of Landfall MEA with Hybrid Model and FLOR-FA

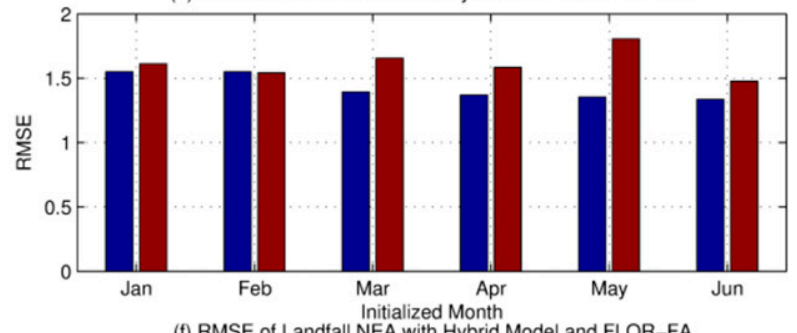

(f) RMSE of Landfall NEA with Hybrid Model and FLOR-FA

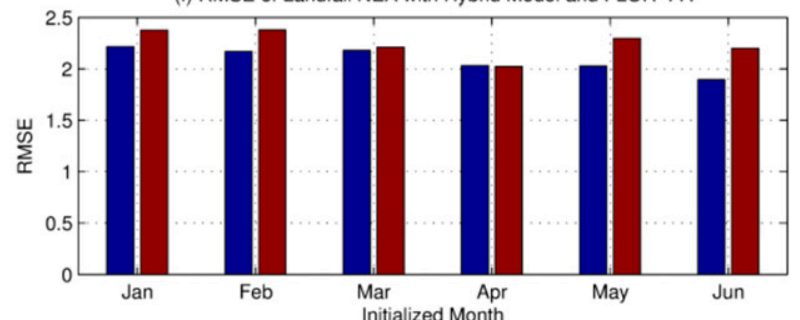

(h) RMSE of Landfall EEA with Hybrid Model and FLOR-FA

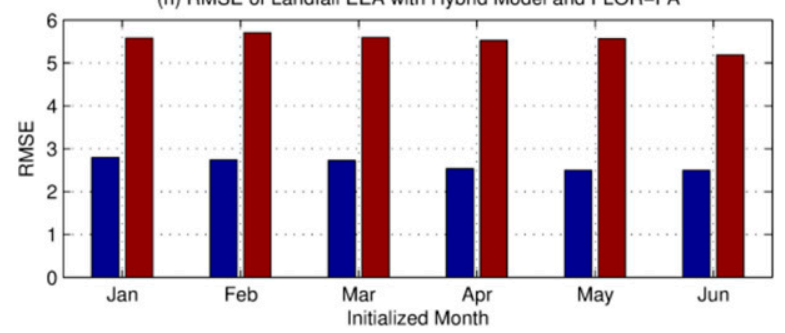

FIG. 11. Correlation coefficient and RMSE in the hybrid model (blue bar) and FLOR-FA (red bar) for TC landfall over SEA, MEA, NEA, and EEA after LOOCV. The black dashed line in the left panels represents the value for which the correlation coefficients are significantly different from zero at the 0.05 significance level.

Figure 8 illustrates that the hybrid models outperform FLOR-FA in predicting WNP TC frequency for all initialization months in terms of correlation coefficient and RMSE. FLOR-FA performs the best in January and the worst in March in the prediction of WNP TC frequency, which is partly related to the mean biases in zonal vertical wind shear in FLOR-FA for different initialization months as documented in Zhang et al. (2016b). The hybrid models built in this study successfully overcome this limitation, and all the predictions made by the hybrid models perform better in terms of correlations and RMSE when closer to the TC season.

\section{b. TC landfall}

We build hybrid models for TC landfall over the EEA and over three subregions (i.e., SEA, MEA, and NEA).
The predictors used for the hybrid models are listed in Table 3 . The predictors are selected based on the strategy which is used to select predictors for WNP TC frequency discussed in section 3a. The predictors for landfalling TCs over SEA, MEA, NEA, and EEA are not exactly the same, suggesting that landfalling TCs over different subregions may be associated with different predictors (climate modes). For example, EMI is only used as a predictor for landfall over NEA while PMM is used for landfall over SEA and EEA (Table 3). PMM, AMM, and NASST have not been used to predict TC landfall over East Asia in the literature yet. Previous studies have discussed the impacts of PMM and NASST on TC genesis and large-scale circulation in observations and model simulations (e.g., Huo et al. 2015; Yu et al. 2015; Zhang et al. 2016a, 2017), suggesting the potential 
TABLE 5. As in Table 4, but for MEA.

\begin{tabular}{cl}
\hline \hline Initial month & Predictors \\
\hline Jan & NASST (Jun-Oct; initial Jan), Niño-3 (Jun-Oct; initial Jan), AMM (Jun-Oct; initial Jan), PDO (Jun-Oct; initial Jan), \\
& and EIO (Jun-Oct; initial Jan) \\
Feb & NASST (Jun-Oct; initial Jan), Niño-3 (Jun-Oct; initial Jan), AMM (Jun-Oct; initial Jan), PDO (Jun-Oct; initial Feb), \\
& and EIO (Jun-Oct; initial Feb) \\
Mar & NASST (Jun-Oct; initial Mar), Niño-3 (Jun-Oct; initial Jan), AMM (Jun-Oct; initial Jan), PDO (Jun-Oct; initial Mar), \\
& and EIO (Jun-Oct; initial Mar) \\
Apr & NASST (Jun-Oct; initial Apr), Niño-3 (Jun-Oct; initial Jan), AMM (Jun-Oct; initial Jan), PDO (Jun-Oct; initial Apr), \\
& and EIO (Jun-Oct; initial Apr) \\
May & NASST (Jun-Oct; initial Feb), Niño-3 (Jun-Oct; initial Jan), AMM (Jun-Oct; initial Jan), PDO (Jun-Oct; initial Apr), \\
& and EIO (Jun-Oct; initial May) \\
Jun & NASST (Jun-Oct; initial Feb), Niño-3 (Jun-Oct; initial Jan), AMM (Jun-Oct; initial Jan), PDO (Jun-Oct; initial Apr), \\
& and EIO (Jun-Oct; initial Jun)
\end{tabular}

influences of PMM/AMM and NASST on East Asian landfalling TCs. PDO is selected by all four hybrid models for landfall over SEA, MEA, NEA, and EEA, suggesting it plays a dominant role in controlling TC landfall over East Asia. The predictive skill of the predictors is high and significant for all initial months (Fig. 9). The STH index based on 850-hPa geopotential height is well predicted with FLOR-FA (Fig. 9). The predictive skill of PMM, Niño-3, and NASST is shown in Fig. 6.

\section{1) LANDFALl OVER SOUTHERn EAST ASIA}

Landfalling TCs over SEA are strongly associated with PMM, NASST, Niño-3, AMM, and PDO, which are used as predictors for the hybrid model (Table 4). The predictors related to TC landfalls over SEA can be calculated from SST and 10-m surface winds. FLOR-FA has high predictive skill for SST and PMM as discussed in section 3a. Using the closer-gets-richer strategy, the predictive skill of the hybrid model for SEA landfall is high for the period 1980-2015 (Fig. 10). The correlation coefficient between predicted and observed TC landfall over SEA increases from 0.52 to 0.64 as we initialize the forecasts from January to June after LOOCV (Fig. 10); for the same lead times, the RMSE of the hybrid model decreases from 1.87 to 1.64 (Fig. 10). A sharp decrease in the frequency of SEA landfalling TCs is observed since 1998, probably associated with the decadal change of WNP TC activity where there is less TC activity in SEA and more TC activity around Taiwan and the East China Sea (Liu and Chan 2013; Lin and Chan 2015). FLOR-FA fails to predict this decrease in SEA landfalling TCs while the hybrid model successfully captures it (Fig. 10). Furthermore, FLOR-FA predicts much less SEA TC landfalls than the observations (Fig. 10). The "perfect prediction" produces a correlation of 0.57 and an RMSE of 1.74 , which is close to the prediction made by the hybrid model.
The year-to-year variation of SEA landfall is much better predicted in the hybrid model than in FLOR-FA, as indicated by the values of the correlation coefficient and RMSE (Fig. 11). For the different initialization months, the results from the hybrid models are very impressive, with high values of correlation coefficient and low RMSE. The performance increases as we reduce the lead time, and it is higher than what we obtain with FLOR-FA. The relatively poor performance of FLOR-FA in predicting SEA may be associated with the eastward shift in TC genesis and density in the WNP. The RMSE in the hybrid model is around half of that in FLOR-FA, suggesting a major improvement in the prediction by the hybrid model (Fig. 11).

\section{2) LANDFAll OVER MidDle EAST ASIA}

NASST, Niño-3, AMM, PDO, and EIO are used as predictors to build hybrid models for MEA landfalling TCs (Tables 3 and 5). All the predictors are related to SST. Previous studies have discussed the modulation of such climate modes or SST anomalies on East Asia landfalling TCs or WNP TC activity, as summarized in section 2b. EIO strongly modulates TC landfall over the Korean Peninsula by mediating the subtropical high (Choi et al. 2015). AMM is obtained from SST and 10-m surface winds. Figure 12 illustrates the predicted AMM in FLOR-FA, which satisfactorily captures the north part of the AMM. The southern part of the AMM with cooling, however, is not well simulated in FLOR-FA, similar to the results in Zhang et al. (2017). Starting from forecasts initialized in March, the predicted AMM has its warming center in the tropical equatorial Atlantic while the warming center in the observations is located in the tropical North Atlantic (Fig. 12). The correlation coefficients between the observed and predicted AMM index are statistically significant at the 0.05 level at all lead months (Fig. 9). The correlation coefficients between the predicted and observed MEA TC landfalls are 

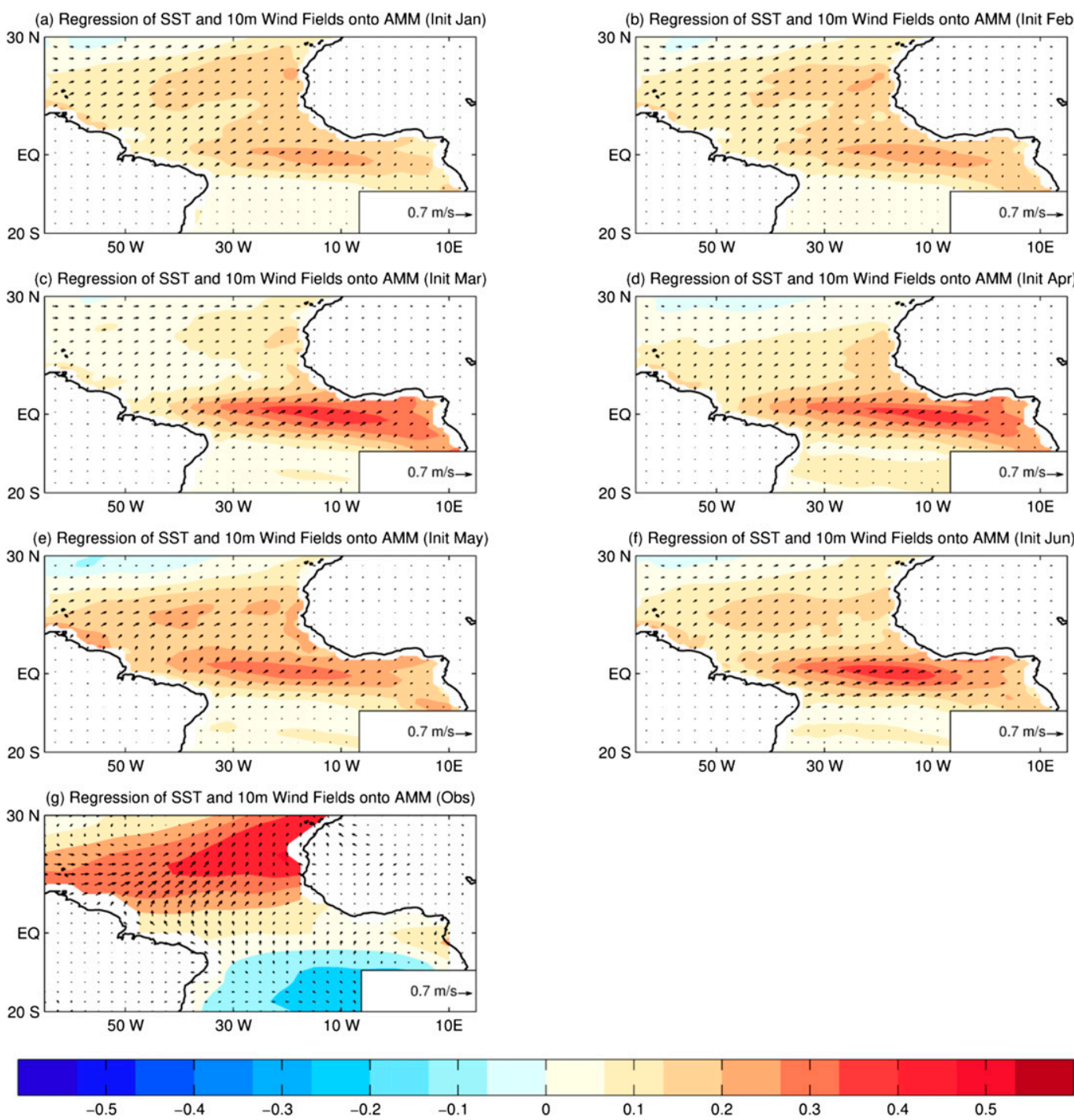

FIG. 12. Predicted AMM with FLOR-FA in initialization months January-June and observed AMM represented by SST anomalies (shading; ${ }^{\circ} \mathrm{C}$ ) and 10 -m surface wind fields (vector; $\mathrm{m} \mathrm{s}^{-1}$ ).
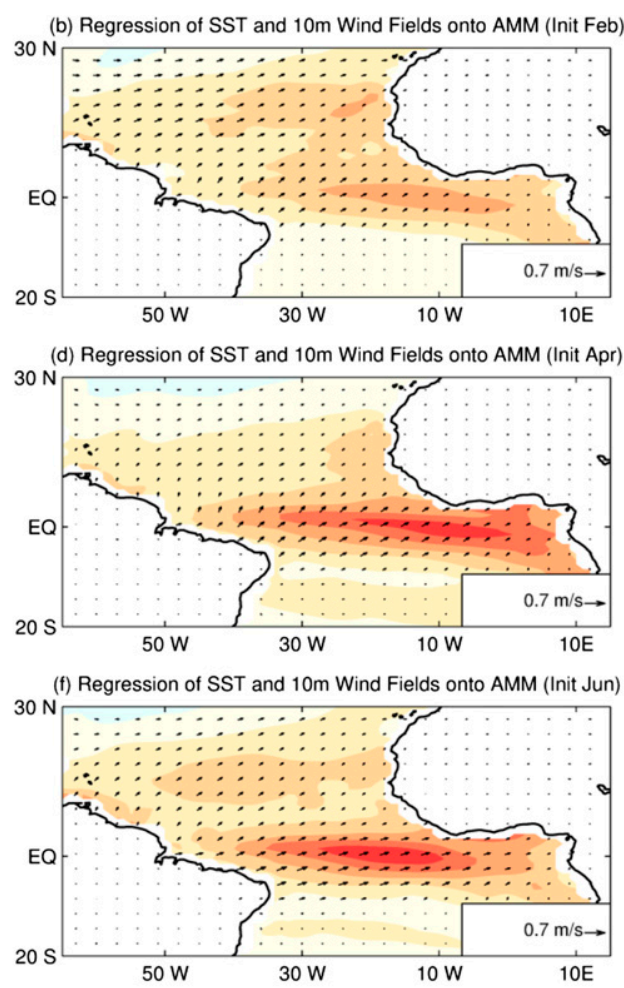

statistically significant except for those initialized in January and February after LOOCV (Fig. 13). The "perfect prediction" using observed predictors leads to a correlation of 0.53 and an RMSE of 1.32 , with skill higher than that of the hybrid model (Table 2 and Fig. 13). The hybrid model improves seasonal forecasting of landfalling TCs over MEA with respect to the results with FLOR-FA in terms of correlation and RMSE (Fig. 13). In general, the predictive skill of the hybrid model for SEA TC landfall is higher than that for MEA TC landfall (Figs. 10 and 13).

\section{3) LANDFALL OVER NORTHERN EAST ASIA}

The predictors for TC landfall over NEA include EMI, Niño-3.4, STH, and the PDO (Table 6). The predictors have strong influences on TC landfall over Japan and the Korean Peninsula (Fan 2007; Zhang et al. 2012; Wang et al. 2013). The STH index is calculated based on 850-hPa GPH anomalies in the western Pacific (Wang et al. 2013). The predictive skill of FLOR-FA for $850-\mathrm{hPa}$ GPH is high for all initialization months using correlation coefficient as a measurement of the skill (Fig. 14). The correlation between predicted and observed $850-\mathrm{hPa}$ GPH is statistically significant in the domain for STH index for all initialization months (Fig. 14). The correlation coefficients between the predicted and observed NEA landfall increase from 0.18 (January initialized) to 0.49 (June initialized), while RMSE decreases from 2.22 to 1.90 for the same initialization months after LOOCV. The perfect prediction 

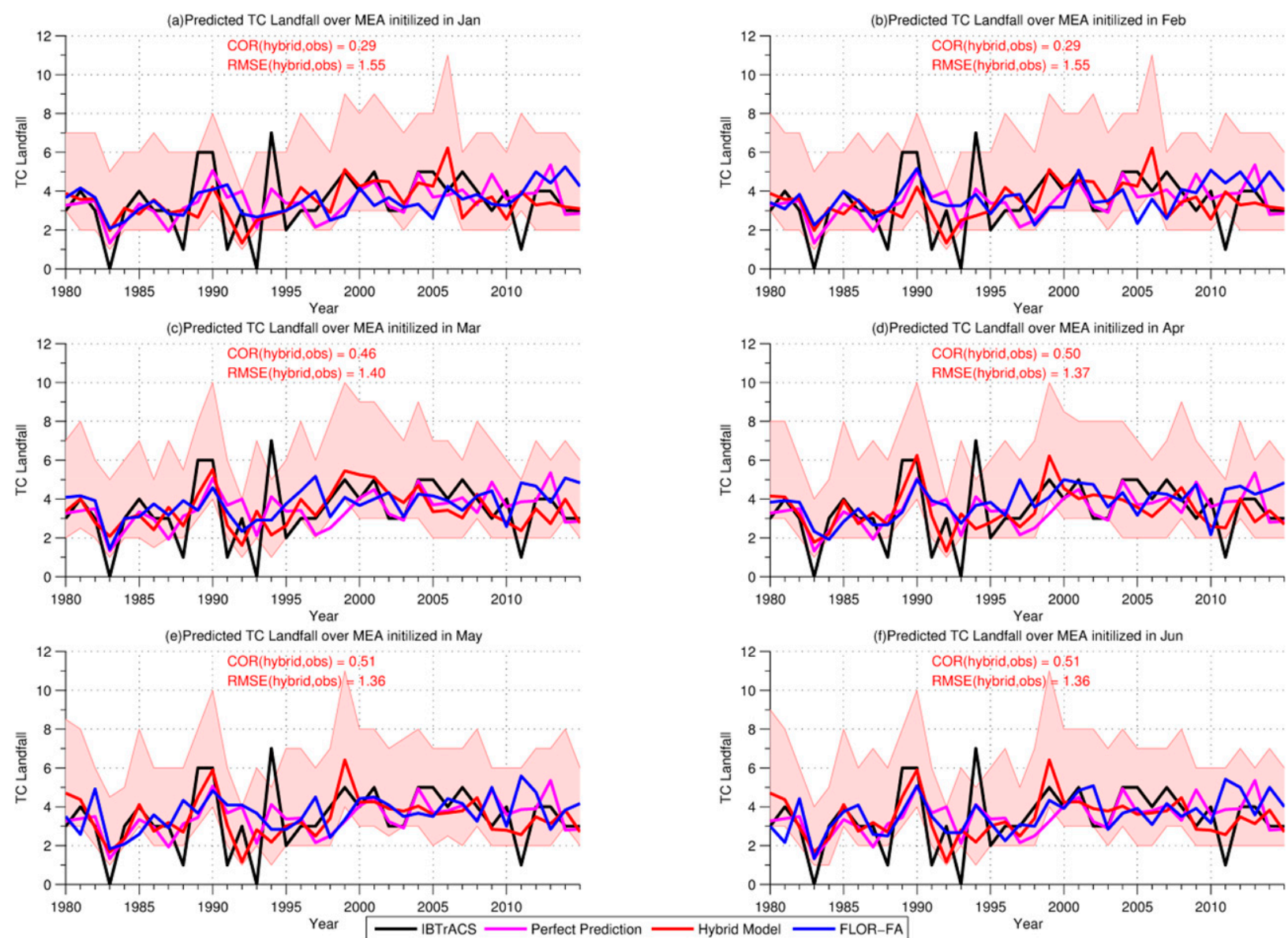

FIG. 13. As in Fig. 7, but for TC landfall over MEA.

produces a correlation of 0.45 and an RMSE of 1.92, close to the prediction derived from the hybrid model. The results from the hybrid model represent a significant improvement over what we obtained using FLOR-FA (Fig. 15).

\section{4) LANDFALl OVER THE ENTIRE EAST ASIAN AREA}

PMM, NASST, PDO, and EIO are used to build hybrid models for TC landfall over EEA (Table 7). The four predictors are calculated from SST and 10-m surface winds, and FLOR-FA exhibits high skill in reproducing those predictors (Fig. 9).

The predictive skill of the hybrid model increased from January-initialized (correlation coefficient equal to 0.37 and RMSE equal to 2.79) to June-initialized (correlation coefficient equal to 0.55 and RMSE equal to 2.49) after LOOCV (Fig. 16). The RMSE of the hybrid model for the prediction of EEA landfall is much lower than that of FLOR-FA (Fig. 16), suggesting significant improvements made by the hybrid model. The perfect prediction produces a correlation of 0.68 and an RMSE

TABLE 6. As in Table 4, but for NEA.

\begin{tabular}{cl}
\hline \hline Initial month & \multicolumn{1}{c}{ Predictors } \\
\hline Jan & Niño-3 (Jun-Oct; initial Jan), EMI (Jun-Oct; initial Jan), STH (Jun-Oct; initial Jan), and PDO (Jun-Oct; initial Jan) \\
Feb & Niño-3 (Jun-Oct; initial Jan), EMI (Jun-Oct; initial Feb), STH (Jun-Oct; initial Feb), and PDO (Jun-Oct; initial Feb) \\
Mar & Niño-3 (Jun-Oct; initial Jan), EMI (Jun-Oct; initial Mar), STH (Jun-Oct; initial Mar), and PDO (Jun-Oct; initial Mar) \\
Apr & Niño-3 (Jun-Oct; initial Jan), EMI (Jun-Oct; initial Mar), STH (Jun-Oct; initial Apr), and PDO (Jun-Oct; initial Apr) \\
May & Niño-3 (Jun-Oct; initial Jan), EMI (Jun-Oct; initial Mar), STH (Jun-Aug; initial Apr), and PDO (Jun-Oct; initial May) \\
Jun & Niño-3 (Jun-Oct; initial Jan), EMI (Jun-Oct; initial Mar), STH (Jun-Oct; initial Apr), and PDO (Jun-Oct; initial May) \\
\hline
\end{tabular}




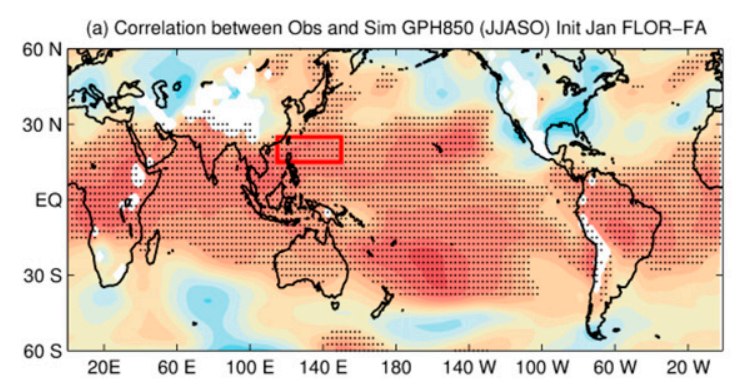

(c) Correlation between Obs and Sim GPH850 (JJASO) Init Mar FLOR-FA
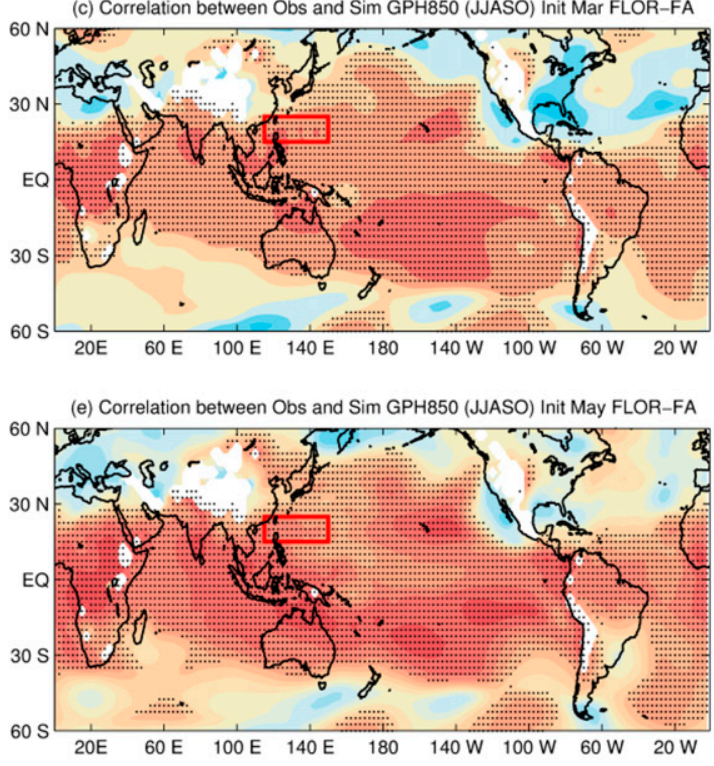

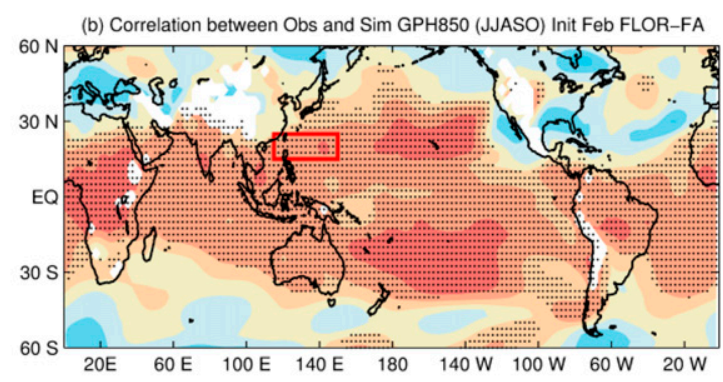

(d) Correlation between Obs and Sim GPH850 (JJASO) Init Apr FLOR-FA
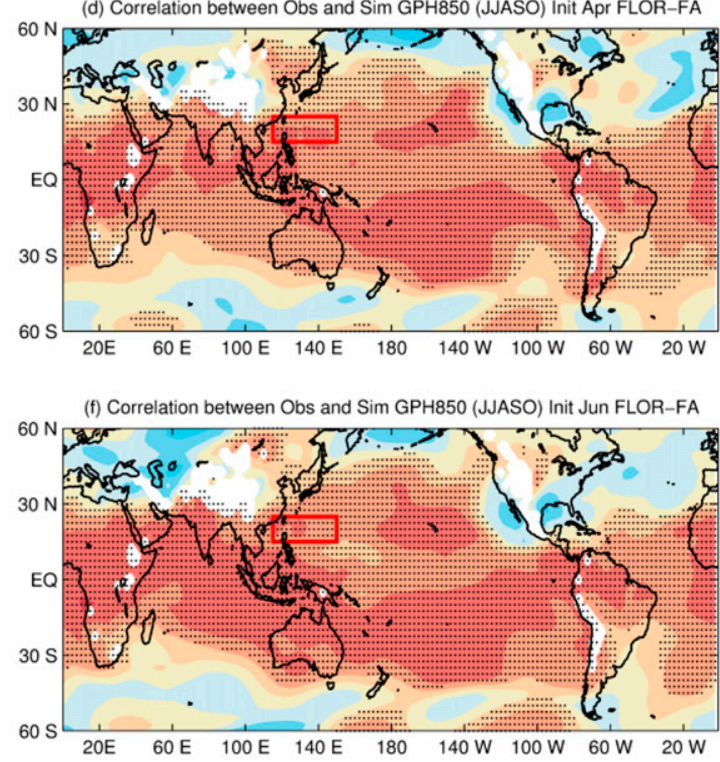

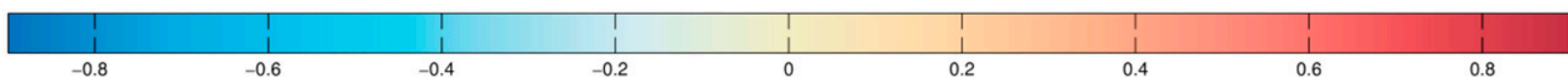

FIG. 14. Pointwise correlation coefficient between predicted (FLOR-FA) and observed 850-hPa GPH for different initialized months (January-June). Stippled regions are those statistically significant at the 0.05 significance level. The red rectangle in each panel represents the domain used for calculating the STH index as in Wang et al. (2013).

of 2.12, slightly higher than the prediction derived from the hybrid model (Table 2). The hybrid model outperforms FLOR-FA for almost all lead months (Figs. 8 and 16).

\section{Discussion and conclusions}

The prediction of WNP TC frequency and TC landfall over East Asia has been the topic of much research over the decades. Both statistical and dynamic models have been used to improve the seasonal prediction of WNP TC frequency and TC landfall over East Asia, with the statistical-dynamical (i.e., hybrid) models representing a very promising path ahead. The skill of dynamic models (AGCMs and CGCMs) in simulating TCs has improved significantly over the last decade or so. However, the skill of climate models is still limited by uncertainty in climate modeling, low spatial resolution to resolve TCs (especially intense TCs), and lack of thorough understanding and representation of physical processes related to TC genesis, development, and tracking. Although the simulation of TC frequency or landfall by climate models still needs improvements, climate models can simulate reasonably well the large-scale circulation or climate modes that are essential in controlling TC activity, providing a good opportunity to improve the seasonal predictions of TCs using hybrid models. Hybrid models, which are based on simulated largescale circulation or climate modes and statistical links between the simulated climate modes/circulation and observed TCs, have proven highly skillful in producing a seasonal prediction of TCs. Successful predictions of TC frequency and landfall using hybrid models, therefore, not only depend on the capability of the dynamic model to reproduce the observed 

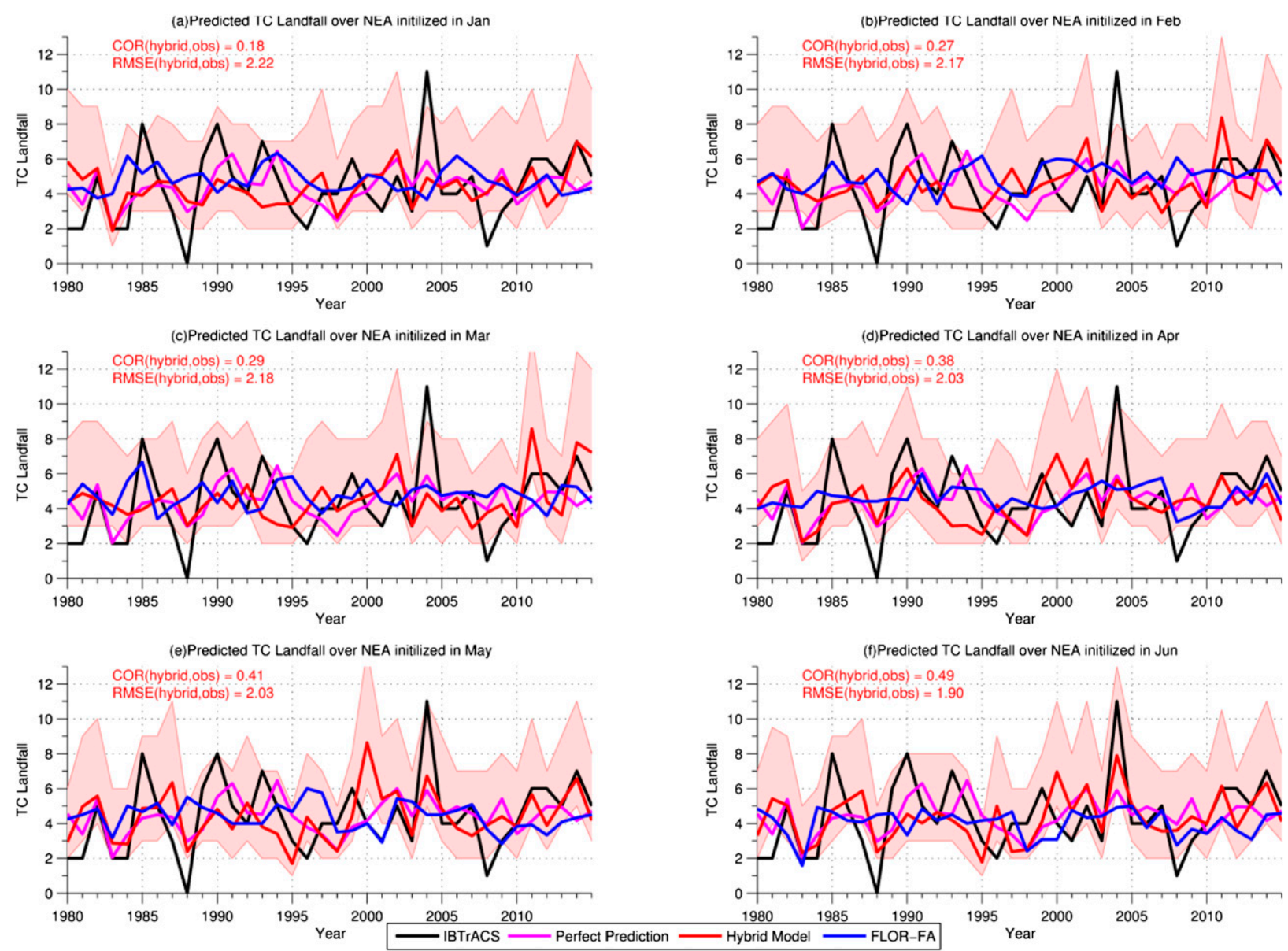

FIG. 15. As in Fig. 7, but for TC landfall over NEA.

climate conditions but also require a better understanding of statistical associations between TCs and climate modes.

Recent studies have found new links between climate modes (e.g., PMM, NASST, SSTG, and STH) and WNP TC activity or East Asian landfalling TCs. By using the "closer-gets-richer" strategy, we employ all available dynamical forecasts in and prior to the initialization month of interest to build hybrid models. The developed hybrid models make substantial improvements in predicting WNP TC frequency and East Asian landfall TCs by using predictors (e.g., PMM and NASST) and the closer gets richer strategy.

TABLE 7. As in Table 4, but for EEA.

\begin{tabular}{|c|c|}
\hline Initial month & Predictors \\
\hline Jan & $\begin{array}{l}\text { PMM (Feb-Jun; initial Jan), NASST (Jun-Oct; initial Jan), PDO (Jun-Oct; initial Jan), and EIO } \\
\text { (Jun-Oct; initial Jan) }\end{array}$ \\
\hline Feb & $\begin{array}{l}\text { PMM (Feb-Jun; initial Jan), NASST (Jun-Oct; initial Feb), PDO (Jun-Oct; initial Feb), and EIO } \\
\text { (Jun-Oct; initial Feb) }\end{array}$ \\
\hline Mar & $\begin{array}{l}\text { PMM (Feb-Jun; initial Jan), NASST (Jun-Oct; initial Feb), PDO (Jun-Oct; initial Mar), and EIO } \\
\text { (Jun-Oct; initial Mar) }\end{array}$ \\
\hline Apr & $\begin{array}{l}\text { PMM (Feb-Jun; initial Jan), NASST (Jun-Oct; initial Feb), PDO (Jun-Oct; initial Apr), and EIO } \\
\text { (Jun-Oct; initial Apr) }\end{array}$ \\
\hline May & $\begin{array}{l}\text { PMM (Feb-Jun; initial Jan), NASST (Jun-Oct; initial Apr), PDO (Jun-Oct; initial Apr), and EIO } \\
\text { (Jun-Oct; initial May) }\end{array}$ \\
\hline Jun & $\begin{array}{l}\text { PMM (Feb-Jun; initial Jan), NASST (Jun-Oct; initial Apr), PDO (Jun-Oct; initial Apr), and EIO } \\
\text { (Jun-Oct; initial May) }\end{array}$ \\
\hline
\end{tabular}



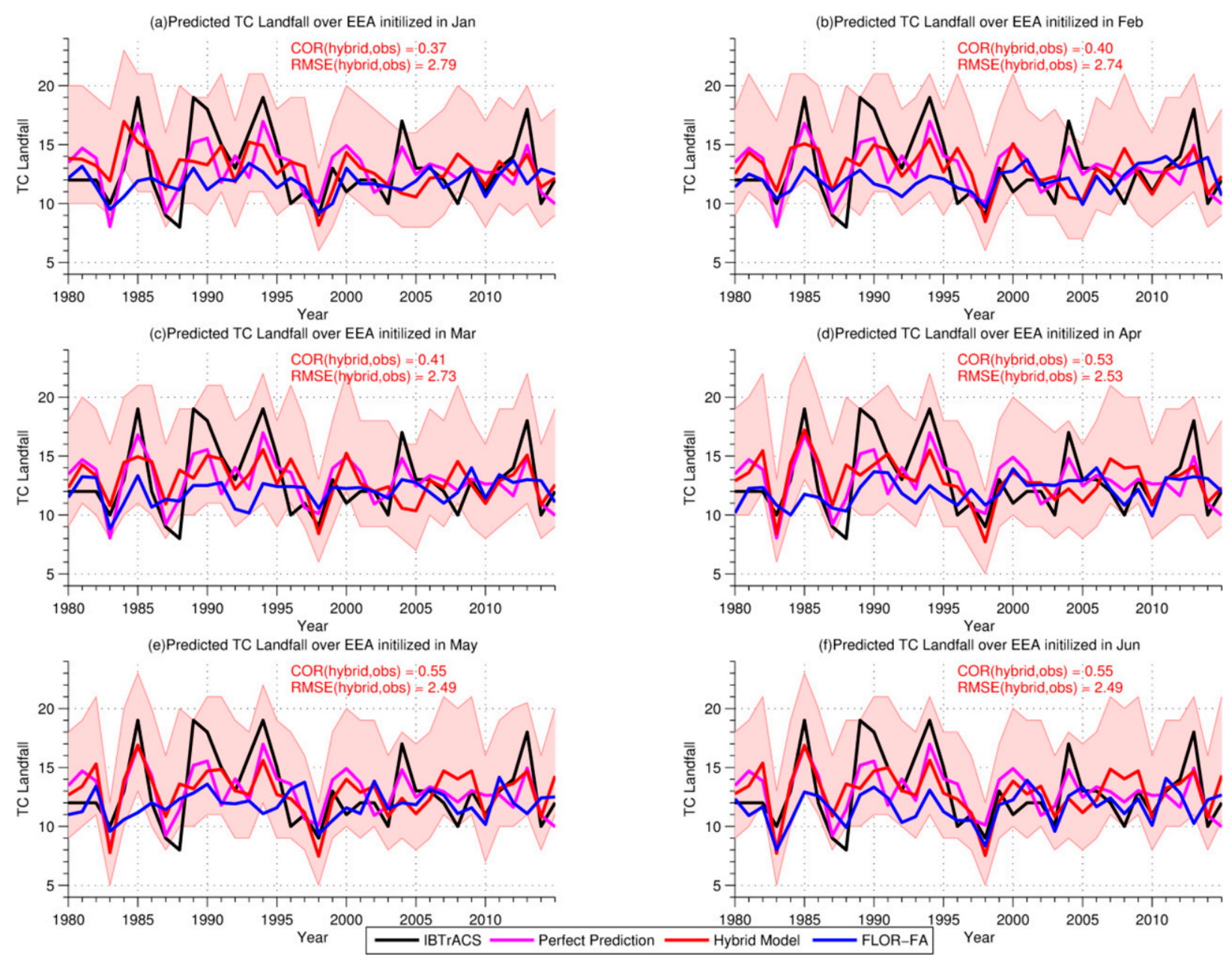

FIG. 16. As in Fig. 7, but for TC landfall over EEA.

Our main findings can be summarized as follows:

1) The hybrid model for basinwide WNP TC frequency uses PMM, NASST, SSTG, and Niño-3 as predictors. The predictive skill of this model for WNP TC frequency increases from the longest (January initialized) to the shortest (June initialized) lead time in terms of correlation and RMSE. The hybrid model outperforms FLOR-FA in predicting WNP TC frequency for all lead months. The predictive skill in hybrid models gets better when closer to the TC season, with values of the correlation coefficient from 0.56 (January) to 0.69 (June).

2) The hybrid models for TC landfall over the three subregions of the East Asian coast and its entirety (i.e., SEA, MEA, NEA, and EEA) show substantial improvement compared with FLOR-FA in terms of correlation coefficient and RMSE. The hybrid model performs the best for the prediction of TC landfall over SEA. The correlation coefficient between predicted and observed TC landfall over SEA increases from 0.52 (for January) to 0.64 (for June). The correlation coefficient between predicted and observed TC landfall over MEA increases from 0.29 in January to 0.51 in June. The correlation coefficient between predicted and observed TC landfall over NEA increases from 0.18 in January to 0.49 in June. The correlation coefficient between predicted and observed TC landfall over EEA increases from 0.37 in January to 0.55 in June.

3) The hybrid models substantially reduce the RMSE of landfalling TCs over SEA and the entire East Asian area compared with FLOR-FA, supporting the idea that the hybrid models can be used for the seasonal prediction of TC landfall over East Asia and its subregions.

This study produces satisfactory prediction results compared with existing studies. Huang and Chan (2014) 
TABLE 8. Summary of the forecasts for the upcoming 2016 WNP TC season (TC frequency) initialized in June 2016; " $P$ (count $>19$ )" indicates the probability of exceeding $19 \mathrm{TCs}$, and so on.

\begin{tabular}{lcccc}
\hline \hline \multicolumn{1}{c}{ WNP TCF } & Mean count & $P($ count $>19)$ & $P($ count $>25)$ & $P($ count $\leq 10)$ \\
\hline Climatology (1980-2015) & 19.0 & 0.44 & 0.07 & 0.02 \\
Hybrid model (2016) & 15.6 & 0.16 & 0.01 & 0.09 \\
\hline
\end{tabular}

reported that the correlation between predicted and observed WNP TC frequency is 0.55 with a LOOCV for 1980-2001 using a regional climate model (RegCM) to dynamically downscale the National Centers for Environmental Prediction Climate Forecast System version 2 (NCEP CFSV2) hindcasts. The period of our study is 1980-2015, which is longer than Huang and Chan (2014). The values of the correlation coefficient and RMSE between the observed and predicted WNP TC frequency for 1982-2012 in a hybrid model (multiple linear regression model) range from 0.73 to 0.79 and from 2.75 to 3.11, respectively, using NCEP CFSV2 ( $\mathrm{Li}$ et al. 2013). Our approach produces values of the correlation coefficient and RMSE ranging from 0.56 to 0.69 and from 2.77 to 3.21. Li et al. (2013) used domains that are obtained from the spatial domains based on correlation analysis between observed predictand and large-scale environmental variables which may be different from those derived from the model simulations. The predictions of TC landfall in SEA, MEA, NEA and EEA based on Huang and Chan (2014) have correlation coefficients of $0.70,0.16,0.58$ and 0.27 for the period 2000 10 while those in our study are $0.64,0.51,0.49$ and 0.55 at the shortest lead time for the period 1980-2015. Sun and Ahn (2011) reported that a coupled climate model [the Pusan National University (PNU) CGCM] exhibited virtually no forecasting ability in predicting 6-9- and 35-month leads for landfalling TCs over East Asia. Therefore, this study produces results that compare very favorably to (often better than) previously published studies in terms of overall skill and persistence across different lead times.

For the upcoming TC season of 2016, the hybrid model predicts a below average number of WNP TCs (Table 8). The hybrid model forecasts that the upcoming season has a lower expected TC count than the average over 1980-2015, along with a lower probability of an extreme high number ( $>25$ TCs) of TCs. Moreover, the hybrid model forecasts a higher probability of an inactive TC season ( $\leq 10 \mathrm{TCs}$ ) than climatology. Similar predictions for the probability of TC landfalls are included in the online supplemental material. It is noted that the skill of the hybrid model depends heavily on whether the predictors of the hybrid model can be well predicted by FLOR-FA. The prediction of expected TC count in the TC season of 2016 is 20.5 when using the observed PMM index (1.9) averaged over FebruaryJune 2016, which is higher than 15.6 when using the predicted PMM index $(-1.4)$ over the same months.

Previous studies have reported that the sample size of regression analysis should be over 10 times the number of predictors (Draper and Smith 1998; Ryan 2008). Although we have used LOOCV to validate the prediction model, the prediction models are still at the risk of overfitting. Our future study will focus on further improving the prediction model by reducing the number of predictors. This can be achieved by applying principal component analysis to the selected variables and using principal components as predictors.

The improvement in predictive skill of the hybrid models is partly due to our better understanding of the physical mechanisms underlying changes in WNP and East Asia landfalling TCs over the years. This strongly encourages us to further examine the climate variability of WNP TC genesis and East Asian landfall, which are highly useful to improve the predictive skill of the statistical and hybrid models. This study indicates that TC landfalls over different parts of the East Asian coast are associated with different climate drivers (Table 2). In particular, we found that PMM and North Atlantic SST anomalies (e.g., NASST and AMM) can improve the predictive skill of the hybrid models for the frequencies of WNP and East Asia landfalling TCs. The PMM and North Atlantic SST anomalies (e.g., NASST and AMM) should be considered when meteorological agencies/ institutions build statistical or hybrid forecast models for WNP and East Asia landfalling TCs.

Acknowledgments. The authors are grateful to three anonymous reviewers for insightful comments. The authors are grateful to Baoqiang Xiang and Carlos Gaitan for their valuable comments on an earlier version of this paper. This material is based in part upon work supported by the National Science Foundation under Grants AGS-1262091 and AGS-1262099.

\section{APPENDIX}

\section{Tracking Algorithm}

The tracker is developed to track TCs from 6-h climate simulations. This tracker was also employed in Zhang 
et al. (2016a,b,c, 2017) and Murakami et al. (2016a). The tracking processes are based on key variables such as temperature, sea level pressure (SLP), and 10-m wind. The tracking procedures are described as follows:

1) Local minima of the smoothed SLP field are found. The location of the center is properly adjusted by fitting a biquadratic function to the SLP and locating the center at the minimum.

2) Closed contours in an interval of $2 \mathrm{hPa}(d p)$ around every single SLP low center. The $N$ th contour is marked as the contiguous region surrounding a low central pressure $P$ with pressures lower than $d p \times$ $N+P$, as detected by a "flood fill" algorithm. It is noted that the contours are not required to be circular, and a maximum radius of $3000 \mathrm{~km}$ will be searched from each candidate low center.

$3)$ If the algorithm detects contours that are close enough, the low is counted as a TC center. In this way, the tracker attempts to find all closed contours in the vicinity of the low center within a certain distance from the low center and without entering contours belonging to another low. The maximum $10-\mathrm{m}$ wind inside the set of closed contours is taken as the maximum wind speed at that time for the storm.

4) Warm cores are detected via similar processes: closed $1{ }^{\circ} \mathrm{C}$ contours for FLOR are found surrounding the maximum temperature anomaly $t_{a}$ within a TC's identified contours, no more than $1^{\circ}$ from the low center. This contour must have a radius smaller than $3^{\circ}$ in distance. If there is not such a core, it should not be marked as a warm-core low center, although the center is not rejected.

5) TC centers are combined into a track by taking a low center at time $T-d t$, extrapolating its motion forward $d t$, and then seeking storms within $750 \mathrm{~km}$. It is noted that a deeper low center has higher priority of tracking.

6) The following criteria are required to pick up the final TCs:

(i) At least $72 \mathrm{~h}$ of total detection lifetime (not necessarily consecutive).

(ii) At least 48 cumulative (not necessarily consecutive) hours with a warm core.

(iii) At least 36 consecutive hours of a warm core with winds greater than $17.5 \mathrm{~m} \mathrm{~s}^{-1}$.

(iv) TC genesis should be confined equatorward of $40^{\circ} \mathrm{N}$.

\section{REFERENCES}

Ashok, K., S. K. Behera, S. A. Rao, H. Weng, and T. Yamagata, 2007: El Niño Modoki and its possible teleconnection. J. Geophys. Res., 112, C11007, doi:10.1029/2006JC003798.
Au-Yeung, A. M., and J. L. Chan, 2012: Potential use of a regional climate model in seasonal tropical cyclone activity predictions in the western North Pacific. Climate Dyn., 39, 783-794, doi:10.1007/s00382-011-1268-x.

Camp, J., M. Roberts, C. MacLachlan, E. Wallace, L. Hermanson, A. Brookshaw, A. Arribas, and A. A. Scaife, 2015: Seasonal forecasting of tropical storms using the Met Office GloSea5 seasonal forecast system. Quart. J. Roy. Meteor. Soc., 141, 2206-2219, doi:10.1002/qj.2516.

Carton, J. A., X. Cao, B. S. Giese, and A. M. Da Silva, 1996: Decadal and interannual SST variability in the tropical Atlantic Ocean. J. Phys. Oceanogr., 26, 1165-1175, doi:10.1175/ 1520-0485(1996)026<1165:DAISVI $>2.0 . \mathrm{CO} ; 2$.

Chan, J. C. L., 2000: Tropical cyclone activity over the western North Pacific associated with El Niño and La Niña events. J. Climate, 13, 2960-2972, doi:10.1175/1520-0442(2000)013<2960: TCAOTW $>2.0 . C O ; 2$.

_- 2005: Interannual and interdecadal variations of tropical cyclone activity over the western North Pacific. Meteor. Atmos. Phys., 89, 143-152, doi:10.1007/s00703-005-0126-y. , and M. Xu, 2009: Inter-annual and inter-decadal variations of landfalling tropical cyclones in East Asia. Part I: Time series analysis. Int. J. Climatol., 29, 1285-1293, doi:10.1002/joc.1782.

_ , J.-E. Shi, and C.-M. Lam, 1998: Seasonal forecasting of tropical cyclone activity over the western North Pacific and the South China Sea. Wea. Forecasting, 13, 997-1004, doi:10.1175/ 1520-0434(1998)013<0997:SFOTCA $>2.0 . C O ; 2$.

, —_, and K. S. Liu, 2001: Improvements in the seasonal forecasting of tropical cyclone activity over the western North Pacific. Wea. Forecasting, 16, 491-498, doi:10.1175/ 1520-0434(2001)016<0491:IITSFO > 2.0.CO;2.

_ , K.-S. Liu, M. Xu, and Q. Yang, 2012: Variations of frequency of landfalling typhoons in East China, 1450-1949. Int. J. Climatol., 32, 1946-1950, doi:10.1002/joc.2410.

Chang, Y.-S., S. Zhang, A. Rosati, T. Delworth, and W. Stern, 2013: An assessment of oceanic variability for 1960-2010 from the GFDL ensemble coupled data assimilation. Climate Dyn., 40, 775-803, doi:10.1007/s00382-012-1412-2.

Chen, J.-H., and S.-J. Lin, 2011: The remarkable predictability of inter-annual variability of Atlantic hurricanes during the past decade. Geophys. Res. Lett., 38, L11804, doi:10.1029/ 2011GL047629.

_, and - 2013: Seasonal predictions of tropical cyclones using a $25-\mathrm{km}$-resolution general circulation model. J. Climate, 26, 380-398, doi:10.1175/JCLI-D-12-00061.1.

Chiang, J. C. H., and D. J. Vimont, 2004: Analogous Pacific and Atlantic meridional modes of tropical atmosphere-ocean variability. J. Climate, 17, 4143-4158, doi:10.1175/JCLI4953.1.

_- Y. Kushnir, and A. Giannini, 2002: Deconstructing Atlantic intertropical convergence zone variability: Influence of the local cross-equatorial sea surface temperature gradient and remote forcing from the eastern equatorial Pacific. J. Geophys. Res., 107, 4004, doi:10.1029/2000JD000307.

Choi, K.-S., S. Park, K.-H. Chang, and J.-H. Lee, 2015: A possible relationship between East Indian Ocean SST and tropical cyclone affecting Korea. Nat. Hazards, 76, 283-301, doi:10.1007/s11069-014-1489-5.

Choi, W., C.-H. Ho, J. Kim, H.-S. Kim, S. Feng, and K. Kang, 2016a: A track pattern-based seasonal prediction of tropical cyclone activity over the North Atlantic. J. Climate, 29, 481494, doi:10.1175/JCLI-D-15-0407.1.

- ——, C.-S. Jin, J. Kim, S. Feng, D.-S. R. Park, and J.-K. E. Schemm, 2016b: Seasonal forecasting of intense tropical 
cyclones over the North Atlantic and the western North Pacific basins. Climate Dyn., 47, 3063-3075, doi:10.1007/ s00382-016-3013-y.

Delworth, T. L., and Coauthors, 2006: GFDL's CM2 global coupled climate models. Part I: Formulation and simulation characteristics. J. Climate, 19, 643-674, doi:10.1175/JCLI3629.1.

- Coauthors, 2012: Simulated climate and climate change in the GFDL CM2.5 high-resolution coupled climate model. J. Climate, 25, 2755-2781, doi:10.1175/JCLI-D-11-00316.1.

— warming and North American drought. J. Climate, 28, 38343845, doi:10.1175/JCLI-D-14-00616.1.

Draper, N. R., and H. Smith, 1998: Applied Regression Analysis. 3rd ed. John Wiley \& Sons, 706 pp.

Du, Y., L. Yang, and S.-P. Xie, 2011: Tropical Indian Ocean influence on northwest Pacific tropical cyclones in summer following strong El Niño. J. Climate, 24, 315-322, doi:10.1175/ 2010JCLI3890.1.

Elsner, J. B., and C. P. Schmertmann, 1993: Improving extendedrange seasonal predictions of intense Atlantic hurricane activity. Wea. Forecasting, 8, 345-351, doi:10.1175/ 1520-0434(1993)008<0345:IERSPO > 2.0.CO;2.

— seasonal hurricane modeling. J. Climate, 17, 2813-2827, doi:10.1175/1520-0442(2004)017<2813:AHBATS>2.0.CO;2.

$\longrightarrow$, and - 2006: Prediction models for annual U.S. hurricane counts. J. Climate, 19, 2935-2952, doi:10.1175/JCLI3729.1.

Fan, K., 2007: North Pacific sea ice cover, a predictor for the western North Pacific typhoon frequency? Sci. China, 50D, 1251-1257, doi:10.1007/s11430-007-0076-y.

- 2010: A prediction model for Atlantic named storm frequency using a year-by-year increment approach. Wea. Forecasting, 25, 1842-1851, doi:10.1175/2010WAF2222406.1.

_- and H. Wang, 2009: A new approach to forecasting typhoon frequency over the western North Pacific. Wea. Forecasting, 24, 974-986, doi:10.1175/2009WAF2222194.1.

Farneti, R., T. L. Delworth, A. J. Rosati, S. M. Griffies, and F. Zeng, 2010: The role of mesoscale eddies in the rectification of the Southern Ocean response to climate change. J. Phys. Oceanogr., 40, 1539-1557, doi:10.1175/2010JPO4353.1.

Goh, A. Z.-C., and J. C. L. Chan, 2010: An improved statistical scheme for the prediction of tropical cyclones making landfall in south China. Wea. Forecasting, 25, 587-593, doi:10.1175/ 2009WAF2222305.1.

Gray, W. M., 1984a: Atlantic seasonal hurricane frequency. Part I: El Niño and 30-mb quasi-biennial oscillation influences. Mon. Wea. Rev., 112, 1649-1668, doi:10.1175/1520-0493(1984)112<1649: ASHFPI $>2.0 . \mathrm{CO} ; 2$.

— 1984b: Atlantic seasonal hurricane frequency. Part II: Forecasting its variability. Mon. Wea. Rev., 112, 1669-1683, doi:10.1175/1520-0493(1984)112<1669:ASHFPI > 2.0.CO;2.

— C. W. Landsea, P. W. Mielke Jr., and K. J. Berry, 1993: Predicting Atlantic basin seasonal tropical cyclone activity by 1 August. Wea. Forecasting, 8, 73-86, doi:10.1175/ 1520-0434(1993)008<0073:PABSTC $>2.0 . C O ; 2$.

Grossmann, I., and P. J. Klotzbach, 2009: A review of North Atlantic modes of natural variability and their driving mechanisms. J. Geophys. Res., 114, D24107, doi:10.1029/ 2009JD012728.

Huang, W.-R., and J. C. L. Chan, 2014: Dynamical downscaling forecasts of western North Pacific tropical cyclone genesis and landfall. Climate Dyn., 42, 2227-2237, doi:10.1007/ s00382-013-1747-3.
Huo, L., P. Guo, S. N. Hameed, and D. Jin, 2015: The role of tropical Atlantic SST anomalies in modulating western North Pacific tropical cyclone genesis. Geophys. Res. Lett., 42, 23782384, doi: 10.1002/2015GL063184.

Jia, L., Coauthors, 2015: Improved seasonal prediction of temperature and precipitation over land in a high-resolution GFDL climate model. J. Climate, 28, 2044-2062, doi:10.1175/ JCLI-D-14-00112.1.

Kennedy, J. J., N. A. Rayner, R. O. Smith, D. E. Parker, and M. Saunby, 2011: Reassessing biases and other uncertainties in sea surface temperature observations measured in situ since 1850: 2. Biases and homogenization. J. Geophys. Res., 116, D14104, doi:10.1029/2010JD015220.

Kim, H.-M., and P. J. Webster, 2010: Extended-range seasonal hurricane forecasts for the North Atlantic with a hybrid dynamical-statistical model. Geophys. Res. Lett., 37, L21705, doi:10.1029/2010GL044792.

_ , E. K. M. Chang, and M. Zhang, 2015: Statistical-dynamical seasonal forecast for tropical cyclones affecting New York State. Wea. Forecasting, 30, 295-307, doi:10.1175/WAF-D-14-00089.1.

Kim, O.-Y., H.-M. Kim, M.-I. Lee, and Y.-M. Min, 2017: Dynamical-statistical seasonal prediction for western North Pacific typhoons based on APCC multi-models. Climate Dyn., 48, 71-88, doi:10.1007/s00382-016-3063-1.

Klotzbach, P. J., 2007: Revised prediction of seasonal Atlantic basin tropical cyclone activity from 1 August. Wea. Forecasting, 22, 937-949, doi:10.1175/WAF1045.1.

Knapp, K. R., M. C. Kruk, D. H. Levinson, H. J. Diamond, and C. J. Neumann, 2010: The International Best Track Archive for Climate Stewardship (IBTrACS): Unifying tropical cyclone data. Bull. Amer. Meteor. Soc., 91, 363-376, doi:10.1175/ 2009BAMS2755.1.

Kobayashi, S., and Coauthors, 2015: The JRA-55 Reanalysis: General specifications and basic characteristics. J. Meteor. Soc. Japan, 93, 5-48, doi:10.2151/jmsj.2015-001.

Kossin, J. P., and D. J. Vimont, 2007: A more general framework for understanding Atlantic hurricane variability and trends. Bull. Amer. Meteor. Soc., 88, 1767-1781, doi:10.1175/ BAMS-88-11-1767.

Krishnamurthy, L., G. A. Vecchi, R. Msadek, H. Murakami, A. Wittenberg, and F. Zeng, 2016: Impact of strong ENSO on regional tropical cyclone activity in a high-resolution climate model in the North Pacific and North Atlantic Oceans. J. Climate, 29, 2375-2394, doi:10.1175/JCLI-D-15-0468.1.

Landsea, C. W., G. D. Bell, W. M. Gray, and S. B. Goldenberg, 1998: The extremely active 1995 Atlantic hurricane season: Environmental conditions and verification of seasonal forecasts. Mon. Wea. Rev., 126, 1174-1193, doi:10.1175/1520-0493(1998)126<1174: TEAAHS $>2.0 . \mathrm{CO} ; 2$.

Lehmiller, G., T. Kimberlain, and J. Elsner, 1997: Seasonal prediction models for North Atlantic basin hurricane location. Mon. Wea. Rev., 125, 1780-1791, doi:10.1175/1520-0493(1997)125<1780: SPMFNA $>2.0 . \mathrm{CO} ; 2$.

Li, X., S. Yang, H. Wang, X. Jia, and A. Kumar, 2013: A dynamicalstatistical forecast model for the annual frequency of western Pacific tropical cyclones based on the NCEP Climate Forecast System version 2. J. Geophys. Res. Atmos., 118, 12 061-12 074, doi:10.1002/2013JD020708.

Lin, I.-I., and J. C. L. Chan, 2015: Recent decrease in typhoon destructive potential and global warming implications. Nat. Commun., 6, 7182, doi:10.1038/ncomms 8182.

Liu, K. S., and J. C. L. Chan, 2003: Climatological characteristics and seasonal forecasting of tropical cyclones making landfall 
along the south China coast. Mon. Wea. Rev., 131, 1650-1662, doi:10.1175//2554.1.

—, and — 2013: Inactive period of western North Pacific tropical cyclone activity in 1998-2011. J. Climate, 26, 2614 2630, doi:10.1175/JCLI-D-12-00053.1.

Lu, M.-M., P.-S. Chu, and Y.-C. Lin, 2010: Seasonal prediction of tropical cyclone activity near Taiwan using the Bayesian multivariate regression method. Wea. Forecasting, 25, 1780 1795, doi:10.1175/2010WAF2222408.1.

Luo, J.-J., S. Masson, S. Behera, S. Shingu, and T. Yamagata, 2005: Seasonal climate predictability in a coupled OAGCM using a different approach for ensemble forecasts. J. Climate, 18, 4474-4497, doi:10.1175/JCLI3526.1.

Manganello, J. V., and Coauthors, 2016: Seasonal forecasts of tropical cyclone activity in a high-atmospheric-resolution coupled prediction system. J. Climate, 29, 1179-1200, doi:10.1175/JCLI-D-15-0531.1.

Mantua, N. J., S. R. Hare, Y. Zhang, J. M. Wallace, and R. C Francis, 1997: A Pacific interdecadal climate oscillation with impacts on salmon production. Bull. Amer. Meteor. Soc., 78, 1069-1079, doi:10.1175/1520-0477(1997)078<1069: APICOW $>2.0 . \mathrm{CO} ; 2$.

Marks, F. D., and L. K. Shay, 1998: Landfalling tropical cyclones: Forecast problems and associated research opportunities. Bull. Amer. Meteor. Soc., 79, 305-323, doi:10.1175/ 1520-0477(1998)079<0305:LTCFPA > 2.0.CO;2.

Msadek, R., G. A. Vecchi, M. Winton, and R. G. Gudgel, 2014a: Importance of initial conditions in seasonal predictions of Arctic sea ice extent. Geophys. Res. Lett., 41, 5208-5215, doi:10.1002/2014GL060799.

_ , and Coauthors, 2014b: Predicting a decadal shift in North Atlantic climate variability using the GFDL forecast system. J. Climate, 27, 6472-6496, doi:10.1175/JCLI-D-13-00476.1.

Murakami, H., and Coauthors, 2016a: Statistical-dynamical seasonal forecast of North Atlantic and U.S. landfalling tropical cyclones using the high-resolution GFDL FLOR coupled model. Mon. Wea. Rev., 144, 2101-2123, doi:10.1175/ MWR-D-15-0308.1.

_ - and Coauthors, 2016b: Seasonal forecasts of major hurricanes and landfalling tropical cyclones using a high-resolution GFDL coupled climate model. J. Climate, 29, 7977-7989, doi:10.1175/JCLI-D-16-0233.1.

Newman, M., and Coauthors, 2016: The Pacific decadal oscillation, revisited. J. Climate, 29, 4399-4427, doi:10.1175/ JCLI-D-15-0508.1.

Nicholls, N., 1979: A possible method for predicting seasonal tropical cyclone activity in the Australian region. Mon. Wea. Rev., 107, 1221-1224, doi:10.1175/1520-0493(1979)107<1221: APMFPS $>2.0 . \mathrm{CO} ; 2$.

Pielke, R., 1997: Hurricanes: Their Nature and Impacts on Society. John Wiley \& Sons, 279 pp.

- J. Gratz, C. Landsea, D. Collins, M. Saunders, and R. Musulin, 2008: Normalized hurricane damage in the United States: 1900-2005. Nat. Hazards Rev., 9, 29, doi:10.1061/ (ASCE)1527-6988(2008)9:1(29).

Powell, M. D., and S. H. Houston, 1998: Surface wind fields of 1995 Hurricanes Erin, Opal, Luis, Marilyn, and Roxanne at landfall. Mon. Wea. Rev., 126, 1259-1273, doi:10.1175/ 1520-0493(1998)126<1259:SWFOHE > 2.0.CO;2.

Ryan, T. P., 2008: Modern Regression Methods. 2nd ed. John Wiley \& Sons, $642 \mathrm{pp}$.

Schneider, E. K., B. Huang, Z. Zhu, D. G. DeWitt, J. L. Kinter III, B. P. Kirtman, and J. Shukla, 1999: Ocean data assimilation, initialization, and predictions of ENSO with a coupled GCM. Mon. Wea. Rev., 127, 1187-1207, doi:10.1175/ 1520-0493(1999)127<1187:ODAIAP > 2.0.CO;2.

Servain, J., 1991: Simple climatic indices for the tropical Atlantic Ocean and some applications. J. Geophys. Res., 96, 1513715 146, doi:10.1029/91JC01046.

Sun, J., and J. B. Ahn, 2011: A GCM-based forecasting model for the landfall of tropical cyclones in China. Adv. Atmos. Sci., 28, 1049-1055, doi:10.1007/s00376-011-0122-8.

, and H. Chen, 2011: Predictability of western North Pacific typhoon activity and its factors using DEMETER coupled models. Chin. Sci. Bull., 56, 3474-3479, doi:10.1007/ s11434-011-4640-7.

Tan, P., T. Long, B. Hai, and K. Chanh, 2015: Seasonal forecasting of tropical cyclone activity in the coastal region of Vietnam using RegCM4.2. Climate Res., 62, 115-129, doi:10.3354/ cr01267.

Tao, L., L. Wu, Y. Wang, and J. Yang, 2012: Influence of tropical Indian Ocean warming and ENSO on tropical cyclone activity over the western North Pacific. J. Meteor. Soc. Japan, 90, 127 144, doi:10.2151/jmsj.2012-107.

Vecchi, G. A., and G. Villarini, 2014: Next season's hurricanes. Science, 343, 618-619, doi:10.1126/science.1247759.

—, M. Zhao, H. Wang, G. Villarini, A. Rosati, A. Kumar, I. M. Held, and R. Gudgel, 2011: Statistical-dynamical predictions of seasonal North Atlantic hurricane activity. Mon. Wea. Rev., 139, 1070-1082, doi:10.1175/2010MWR3499.1.

, and Coauthors, 2013: Multiyear predictions of North Atlantic hurricane frequency: Promise and limitations. J. Climate, 26, 5337-5357, doi:10.1175/JCLI-D-12-00464.1.

— , and Coauthors, 2014: On the seasonal forecasting of regional tropical cyclone activity. J. Climate, 27, 7994-8016, doi:10.1175/JCLI-D-14-00158.1.

Villarini, G., and G. A. Vecchi, 2012: North Atlantic power dissipation index (PDI) and accumulated cyclone energy (ACE): Statistical modeling and sensitivity to sea surface temperature changes. J. Climate, 25, 625-637, doi:10.1175/JCLI-D-11-00146.1. , and - 2013a: Multiseason lead forecast of the North Atlantic power dissipation index (PDI) and accumulated cyclone energy (ACE). J. Climate, 26, 3631-3643, doi:10.1175/JCLI-D-12-00448.1.

$\ldots$, and $—, 2013 \mathrm{~b}$ : Multiseason lead forecast of the North Atlantic power dissipation index (PDI) and accumulated cyclone energy (ACE). J. Climate, 26, 3631-3643, doi:10.1175/ JCLI-D-12-00448.1.

,-- , and J. A. Smith, 2010: Modeling the dependence of tropical storm counts in the North Atlantic Basin on climate indices. Mon. Wea. Rev., 138, 2681-2705, doi:10.1175/ 2010MWR3315.1.

_ B. Luitel, G. A. Vecchi, and J. Ghosh, 2017: Multi-model ensemble forecasting of North Atlantic tropical cyclone activity. Climate Dyn., doi:10.1007/s00382-016-3369-z, in press.

Vimont, D. J., and J. P. Kossin, 2007: The Atlantic meridional mode and hurricane activity. Geophys. Res. Lett., 34, L07709, doi:10.1029/2007GL029683.

Vitart, F., 2006: Seasonal forecasting of tropical storm frequency using a multi-model ensemble. Quart. J. Roy. Meteor. Soc., 132, 647-666, doi:10.1256/qj.05.65. , and T. N. Stockdale, 2001: Seasonal forecasting of tropical storms using coupled GCM integrations. Mon. Wea. Rev., 129, 2521-2537, doi:10.1175/1520-0493(2001)129<2521: SFOTSU $>2.0 . \mathrm{CO} ; 2$. 
, D. Anderson, and T. Stockdale, 2003: Seasonal forecasting of tropical cyclone landfall over Mozambique. J. Climate, 16, 3932-3945, doi:10.1175/1520-0442(2003)016<3932: SFOTCL $>2.0 . \mathrm{CO} ; 2$

Wang, B., B. Xiang, and J.-Y. Lee, 2013: Subtropical high predictability establishes a promising way for monsoon and tropical storm predictions. Proc. Natl. Acad. Sci. USA, 110, 2718-2722, doi:10.1073/pnas.1214626110.

Wang, H., and K. Fan, 2007: Relationship between the Antarctic Oscillation in the western North Pacific typhoon frequency. Chin. Sci. Bull., 52, 561-565, doi:10.1007/s11434-007-0040-4.

Wilks, D. S., 2011: Statistical Methods in the Atmospheric Sciences. 3rd ed. International Geophysics Series, Vol. 100, Academic Press, 676 pp.

Xiang, B., and Coauthors, 2015: Beyond weather time scale prediction for Hurricane Sandy and Super Typhoon Haiyan in a global climate model. Mon. Wea. Rev., 143, 524-535, doi:10.1175/MWR-D-14-00227.1.

Xie, S.-P., and S. G. H. Philander, 1994: A coupled oceanatmosphere model of relevance to the ITCZ in the eastern Pacific. Tellus, 46A, 340-350, doi:10.1034/ j.1600-0870.1994.t01-1-00001.x.

Yang, X., and Coauthors, 2013: A predictable AMO-like pattern in the GFDL fully coupled ensemble initialization and decadal forecasting system. J. Climate, 26, 650-661, doi:10.1175/ JCLI-D-12-00231.1.

- and Coauthors, 2015: Seasonal predictability of extratropical storm tracks in GFDL's high-resolution climate prediction model. J. Climate, 28, 3592-3611, doi:10.1175/ JCLI-D-14-00517.1.

Yu, J., T. Li, Z. Tan, and Z. Zhu, 2015: Effects of tropical North Atlantic SST on tropical cyclone genesis in the western North Pacific. Climate Dyn., 46, 865-877, doi:10.1007/ s00382-015-2618-x.

Zhan, R., and Y. Wang, 2016: CFSv2-based statistical prediction for seasonal accumulated cyclone energy (ACE) over the western North Pacific. J. Climate, 29, 525-541, doi:10.1175/ JCLI-D-15-0059.1.

,-- , and C.-C. Wu, 2011: Impact of SSTA in the East Indian Ocean on the frequency of northwest Pacific tropical cyclones: A regional atmospheric model study. J. Climate, 24, 62276242, doi:10.1175/JCLI-D-10-05014.1.

_, — , and M. Wen, 2013: The SST gradient between the southwestern Pacific and the western Pacific warm pool: A new factor controlling the northwestern Pacific tropical cyclone genesis frequency. J. Climate, 26, 2408-2415, doi:10.1175/JCLI-D-12-00798.1.

, _ - and L. Tao, 2014: Intensified impact of east Indian Ocean SST anomaly on tropical cyclone genesis frequency over the western North Pacific. J. Climate, 27, 8724-8739, doi:10.1175/JCLI-D-14-00119.1.

Zhang, Q., Q. Liu, and L. Wu, 2009: Tropical cyclone damages in China 1983-2006. Bull. Amer. Meteor. Soc., 90, 489-495, doi:10.1175/2008BAMS2631.1.

Zhang, S., 2011: A study of impacts of coupled model initial shocks and state-parameter optimization on climate predictions using a simple pycnocline prediction model. J. Climate, $\mathbf{2 4}$, 6210-6226, doi:10.1175/JCLI-D-10-05003.1.

— data assimilation with a biased coupled GCM. Mon. Wea. Rev., 138, 3905-3931, doi:10.1175/2010MWR3326.1.

— M. J. Harrison, A. Rosati, and A. Wittenberg, 2007: System design and evaluation of coupled ensemble data assimilation for global oceanic climate studies. Mon. Wea. Rev., 135, 35413564, doi:10.1175/MWR3466.1.

Zhang, W., H. F. Graf, Y. Leung, and M. Herzog, 2012: Different El Niño types and tropical cyclone landfall in East Asia. J. Climate, 25, 6510-6523, doi:10.1175/JCLI-D-11-00488.1.

_, Y. Leung, and J. C. L. Chan, 2013a: The analysis of tropical cyclone tracks in the western North Pacific through data mining. Part I: Tropical cyclone recurvature. J. Appl. Meteor. Climatol., 52, 1394-1416, doi:10.1175/JAMC-D-12-045.1.

,-- , and $-2013 \mathrm{~b}$ : The analysis of tropical cyclone tracks in the western North Pacific through data mining. Part II: Tropical cyclone landfall. J. Appl. Meteor. Climatol., 52, 14171432, doi:10.1175/JAMC-D-12-046.1.

—, G. Vecchi, H. Murakami, G. Villarini, and L. Jia, 2016a: The Pacific meridional mode and the occurrence of tropical cyclones in the western North Pacific. J. Climate, 29, 381-398, doi:10.1175/JCLI-D-15-0282.1.

_- G. Villarini, G. A. Vecchi, H. Murakami, and R. Gudgel, 2016b: Statistical-dynamical seasonal forecast of western North Pacific and East Asia landfalling tropical cyclones using the high-resolution GFDL FLOR coupled model. J. Adv. Model. Earth Syst., 8, 538-565, doi:10.1002/ 2015 MS000607.

— , and Coauthors, 2016c: Improved simulation of tropical cyclone responses to ENSO in the western North Pacific in the high-resolution GFDL HiFLOR coupled climate model. J. Climate, 29, 1391-1415, doi:10.1175/JCLI-D-15-0475.1.

—, G. A. Vecchi, G. Villarini, H. Murakami, A. Rosati, X. Yang, L. Jia, and F. Zeng, 2017: Modulation of western North Pacific tropical cyclone activity by the Atlantic meridional mode. Climate Dyn., 48, 631-647, doi:10.1007/s00382-016-3099-2.

Zhao, M., I. M. Held, and G. A. Vecchi, 2010: Retrospective forecasts of the hurricane season using a global atmospheric model assuming persistence of SST anomalies. Mon. Wea. Rev., 138, 3858-3868, doi:10.1175/2010MWR3366.1. 